\title{
تأثير التغذية الراجعة علي مستوي أداء مهارة تنفيذ درس التربية الرباضية
}

\section{للطالبات المعلمات}

\author{
* أ.د / بلانش سلامه متياس

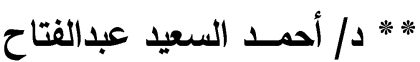 \\ **** أر إيمان محمد مصطفي موسي
}

: مقدمة ومشكلة البحث

تمثل الطبيعة الإنسانية المحور الرئيسي في العملية التربوية الذي يتمثل في ماهية واقع الإنسان ويعتبر ذلك من اهم الموضوعات الحيوية ف الحياة الإنسانية ويعتبر مؤشرا رئيسيا في تحديد الإتجاهات الفكرية والعقلية وبالتالي احيه الحضارة الإنسانية إن حقيقة تقدم مهنة تدريس التربية الرياضية يعتمد في المقام الأول علي ضرورة إعداد وتأهيل معلم تربية رياضية يتمتع بكفاءة وفاعلية عالية حيث تكتسب المهنة إحترامها من خلال الخدمات النافعة التي تقدمها للمجتمع بحيث يلمس أبناء هذا المجتمع أهمية هذه الخدمات ويستشعروا فضلها عليهم . ويعد معلم التربية الرياضية الركن الركين في العملية التعليمية بالمؤسسات التعليمية حيث تتاح لله الفرض التربوية الكثيرة التي لاتتحقق للكثير من المعلمين في المواد الدراسية المختلفة فعن طريقه يمكن الأخذ بيد المتعمين إلي الطريق المقبول إجتماعيا لذلك كان من الزم الضروريات العناية الكاملة بإعداده وتأهيله لمهنة التدريس تأهيلاً يجعله في المكانة اللائقة بتحمل المسئوليات المختلفة في تربية وتنشئة أبناء المجتمع وذخيرته للمستقبل.(T : (1) وإن معلم التربية الرياضية له دور هام في نجاح العملية التربوية وزيادة مردودها ولذا كان لابد من إعداده إعدادا مهنياً كي يتمكن من تحقيق أحسن النتائج المتوقعة في برامج التربية الرياضية ويتوقف نجاح برنامج التذربية الرياضية في بلوغ أهدافها إلي درجة كبيرة علي توفير العدد الكافي من المعلمين وعلي نوعياتهم وكفاءتهم أي علي الإعداد الكمي والكيفي لهح .(ع : 10 (1)

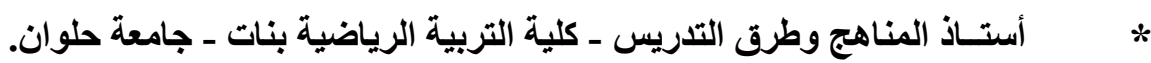

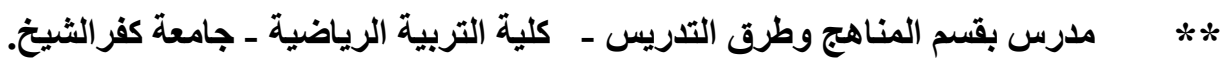
** * * *احثة ماجستير بقسم المناهج وطرق التدريس ـ كلية التربية الرياضية ـ جامعة كفر الثيخ. 
إن المعلم الجيد يساعد تنظيم خبرات المتعلم والمشاركة في عمليات التجديد التربوي فهو يطالب بالتتفيذ والمتابعة ويتعرف علي القصور عند التلاميذ ويضع التصور للعلاج السليم ووضعها موضع (rTV:

إن المعلم يبث المثل العليا في تلاميذه وهو القدوة والمثل الأعلي أمامهم وعلي منواله يسير الكثيرون منهم ويتأثرون بشخصيته ويقلدونه فدور المعلم الإيجابي الناتج عن تأثير التلاميذ بشخصيته كبير والتعليم عن طريق القدوة له أثره الواضح العميق.(V : (1) والطالب في كليات التربية الرياضية عليه أن يتدرب على تلك المهارات التدريسية المختلفة أثناء محاضرات طرق التدريس أوالتربية العملية الداخلية أو أثناء التدريب الميداني حتي يتطور ويرتفع

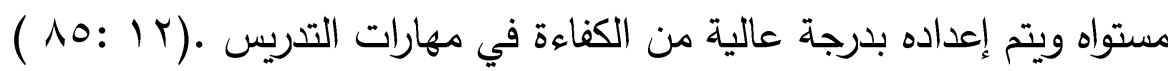
وتعتبر المهارات التدريس بأنها نشاط مهني يتطلب فترة من التدريب المقصود والممارسة المنظمة والخبرة المضبوطة بحيث تؤدي بطريقة جيدة ـ (Y : ب ا ( ) ويقصد بالمهارات التدريسية مجموعة السلوكيات التي يظهرها المعلم في نشاطه التعليمية داخل حجرة الدراسة لتحقيق الأهداف الموضوعة ويظهر في هذا الأداء السلوكي للمعلم والدقة والسرعة التي تمناسب والموقف التعليمي • (90: (9) إن التغذية الراجعة من العوامل الهامة فى تعديل العملية التعليمية فى سبيل المحافظة على جودة المدخلات وتصحيحها أولا بأول ، ويمكن بسهولة أن نلاحظ تأثيرها الهام إذا ما كانت التغذية سلبية ، والتغذية الرجعية تأخذ أشكالا مثل استفاهم المتعلم ، تساؤلاته وتصحيح الاخطاء وهى أشكال ظاهرية تعتبر إطار التعديل فى المدخلات الناتجة عن التغذية الرجعية.(ع : ب0) وتعلم المهارات الحركية في ضوء نظريات التعليم السييرنيتى , يمر بعدة عمليات تبدأ بالمدخلات الحسية , ثم بالمعالجة المعرفية لهذه المدخلات والتى تتضمن عمليات من أهمها الإدراك الحركى بعد كل محاولة ,ويمكن في ضوءها إحداث التعديل اللازم من المدخلات الحسية والخطة

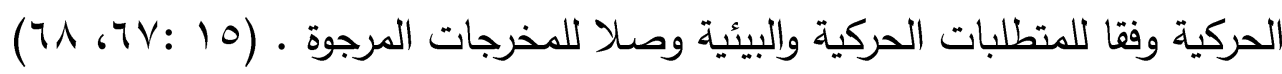
وينظر السلوكين إلى التغذية الراجعة على أنها مثير ترتبط به الأجزاء الاخيرة للإستجابة ولذلك ففى المهارات الحركية المستمرة يتحدد السلوك الحركى من خلال سلسلة إرتباط المثير بالاستجابة حيث تتتج الاستجابة الأولى مثيرا ملائما للتغذية الراجعة ترتبط به الاستجابة التالية وهكذا ـ ( 10 : ع ) 
لذلك يرى الباحثون أهمية إستخدام التغذية الراجعه بمعرفة الأداء المدعمة بإستخدام الفيديو

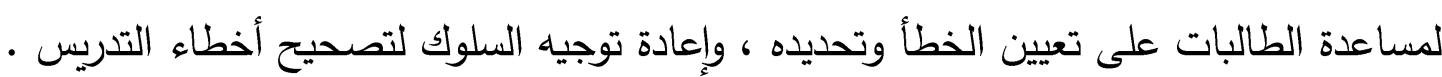
ومن خلال إطلاع الباحثون على العديد من الدراسات التى تتاولت التغذية الراجعة والمهارات التدريسية ووسائل التكنولوجيا كدراسة "محمد سيد عزب عبد الباقى" (1 + ب)(1 (1) ودراسة " آية نبيل

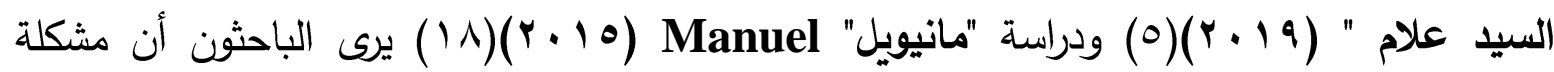
البحث تكمن فى محاولة التعرف على تأثير التغذية الراجعه بمعرفة الاداء على تحسين المهارات التتريسية لطالبات كلية التربية الرياضية . الهمية البحث ومدى الحاجه إلية : يعتبر إعداد الطلاب للعمل فى مجال التدريس أولى مهام كليات التربية الرياضية ، والتربية العملية هى المادة التى تعتبر جوهر عمليات إعداد الطلاب مهنيا ، وذلك من خلال تطوير السلوك المهنى ، وإكسابهم الخبرات اللازمة للعمل بمهنة التدريس ، من خلال تتمية مهاراتهم التدريسية ، وإفساح المجال أمامهم لتطبيق النظريات التربوية التى درسوها تحت إشراف وتوجيه لمساعدتهم على تحمل المسئولية فى مهنة التدريس فى المستقبل . وفى هذه الدراسة يحاول الباحثون الإستفادة من إستخدام تصوير الفيديو ، كأحد وسائل التغذية الراجعة بمعرفة الأداء ، لتوفير معلومات وافيه تتعلق بآداء الطالبات لتحسين المهارات التدريسية لديهن ، حيث سيتم تصوير آداء كل طالبة أثناء تدريس أجزاء الدرس على طالبات المرحلة الإعدادية بمدرسة القرضا ثم إعادة عرض تصوير الفيديو ، مع ملاحظات الموجهة للوقوف على الأخطاء من خلال استخدام الهاتف المحمول كثكل من أشكال التعلم النقال ثم إعادة التدريس مرة أخرى لتلاقيها .

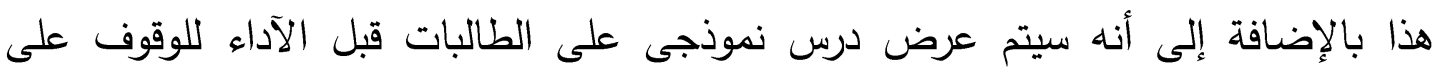
المهارات التدريسية المراد التركيز عليها ، وتوضيح الأهداف التدريسية المراد تحقيقها بوضوح . 
- أولاً : معرفة تأثير إستخدام التغذية الراجعه بمعرفة الأداء على تحسين المهارات التدريسية

$$
\text { لطالبات الكلية من حيث ( التنفيذ). }
$$

- ـ ثانياً: بناء إستمارة لتقويم المهارات التدريسية لطالبات التربية العملية الخاصة بتنفيذ وتقويم الدرس مت

وإدارة الفصل . n

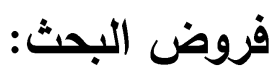

- أولاً : توجد فروق ذات دلالة احصائية بين متوسطي القياسيين القبلي والبعدي للمجموعة

$$
\text { التجرببية في متغير (التنفيذ ) لصالح القياس البعدي. }
$$

- ثانياً : توجد فروق ذات دلالة احصائية بين متوسطي القياسيين القبلي والبعدي للمجموعة

$$
\text { الضابطة في متغير (التنفيذ ) لصالح القياس البعدي. }
$$

- الثاً : توجد فروق ذات دلاله احصائية بين متوسطي القياسين البعديين للمجموعتين التجربية والضابطة فى متغير (التنفيذ)لصالح القياس البعدي للمجموعة التجربية.

\section{المصطاحات المستخدمة:}

\section{التغذية الراجعة :}

التغذية الراجعة هى تلك العملية التى ترتبط بعمليات الإتصال والتواصل , ومن خلالها يدرك الفرد أو الجماعة نتائج إستجابتة أو نمط تلك الإستجابة , وتثير هذه العملية إلى المعلومات التى يتلقاها الفرد أو الجماعة عن ملائمة وكفاية أداتة , وكثيرا ما تئدى المعلومات التى تحملها التغذية

$$
\begin{aligned}
& \text { الرجعية إلى تغير أو تعديل السلوك . (0، : ( ) } \\
& \text { التغذية الراجعه بمعرفة الأداء : }
\end{aligned}
$$

هى معلومات عن طبيعة وشكل الآداء تقدم للمتعلم لمساعدته على إدراك أفضل للموقف، وكلما

$$
\begin{aligned}
& \text { إتسمت هذه المعلومات بالدقة كان لما أثراً كبيراً على التعلم (تعريف إجرائى ) }
\end{aligned}
$$

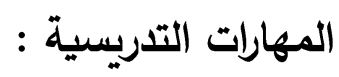


هى الطرق والوسائل والسلوكيات التى يتبعها المعلم لإنجاز مهام التدريس معتمدا على معلوماته ومهاراته وخصائصه الثخصية ، وهى مجموعة الصفات التى يمتلكها المدرس لتعينه على ولى

$$
\text { الوصول للهدف "( } 9 \text { : 109). }
$$

ويمكن تعريفها أيضاً بأنها "عملية تتظيم محتوى الدرس وإعداد المكان والأجهزة اللازمة مع رسم

$$
\begin{aligned}
& \text { خطة واضحة لأسلوب تتفيذه "(تعريف إجرائئ). } \\
& \text { إجراء ات البحث: } \\
& \text { أولاً: منهج البحث }
\end{aligned}
$$

إستخدم الباحثون المنهج التجريبى وذلك لملائمته لطبيعة البحث وذلك باستخدام التصميم التجريبى ذو المجموعتين ، أحداهما تجريبية ، والاخرى ضابطة باستخدام القياس القبلى والبعدى للدجموعتين.

\section{ثانياً: مجتمع وعينة البحث :}

يمثل مجتمع البحث طالبات الفرقة الرابعة بكلية التربية الرياضية جامعة كفر الثيخ للعام

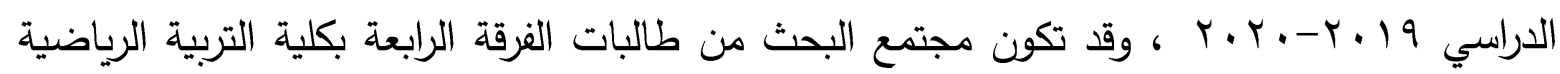

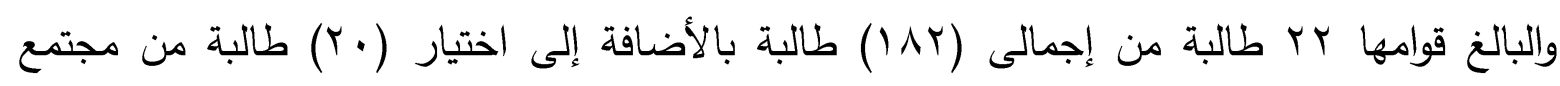

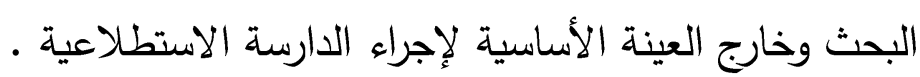

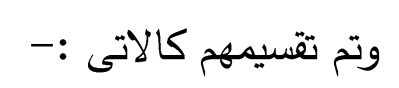

1. المجموعة الضابطة : وقد شملت (11) طالبة يطبق عليها البرنامج التقليدى. r. المجموعة التجربية : وقد شملت (1) بالبة يطبق عليها التغذية الراجعة بمعرفة الأداء.

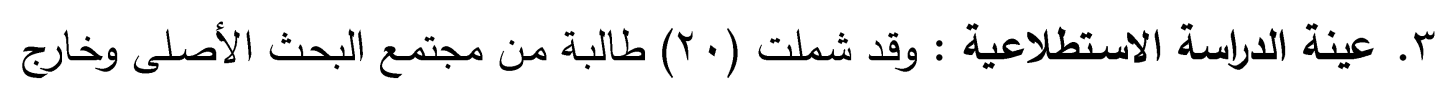

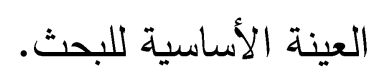

$$
\text { 1اثاثا: مجالات البحث: المجال البشري: }
$$

طالبات الفرقة الرابعة بكلية التربية الرياضية جامعة كفر الثيخ. 
تم تتفيذ وتطبيق البرنامج التدريبى والقياسات القبلية والبعدية بمدرسة القرضا الاعدادية التابعة

لإدارة كفرالثيخ التعليمية.

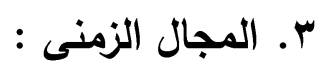

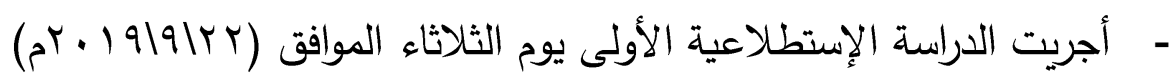

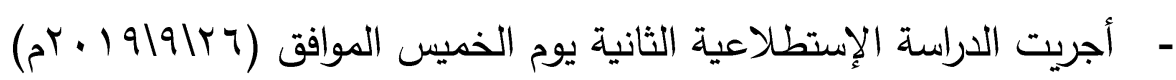

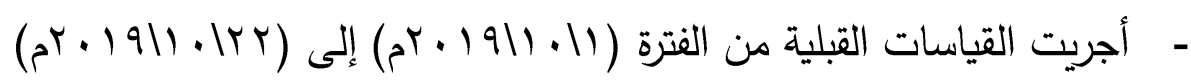

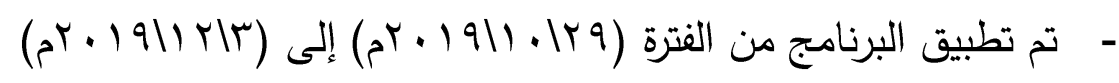

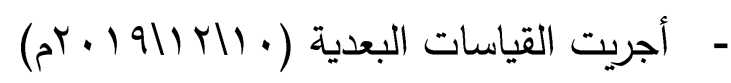

رابعاً: اعداد مواد المعالجة التجريبية :

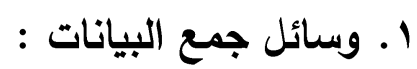

قام الباحثون بتحديد البيانات المستخدمة فى البحث الى مايلى:

ادوات الدلالة على معدل النمو وقد تمثلت فى القياسات التالية :

أ- العمر الزمنى: بالرجوع إلى تاريخ الميلاد "لاقرب سنة"

ب- الطول: بواسطة استخدام جهاز الرستاميتر "لاقرب سنتيمتر"

ج- الوزن: بواسطة الميزان الطبى "لأقرب كيلو جرام".

r ـ الإختبارات المستخدمة فى البحث :

- إختبار القدرات العقلية للذكاء للصغار والكبار " إعداد/سامية الانصارى .

استخدم الباحثون اختبار الذكاء المصور التى قامت بتصميمة د/سامية الانصارى ويتكون

الاختبار من (• (7) سؤال متدرج فى الصعوبة مدتة (0) دقيقة فهذا الاختبار يحتوى على عدد من

الأسئلة الذهنية والاشكال تقيس قدرة المتعلمين على التفكير .

r. المراجع العلمية والدراسات المشابهة:

وذلك بغرض تحديد عبارات إستمارة تقويم طالبات التربية العملية فى محاور إستمارة التقويم

$$
\text { (والتى قام الباحثون بإقتراحها مسبقا على الخبراء ). }
$$


تم إجراء المقابلات الثخصية مع بعض الخبراء من أساتذة التربية الرياضية المتخصصين فى مجال طرق التدريس والتدريب الميدانى وذلك للاتفاق على عبارات إستمارة تقويم طالبة التربية العملية . هـ الملاحضة:

تم إستخدام الملاحظة المقننة وذلك عند تقييم مستوى طالبات عينة البحث من خلال الإستمارة التى قد تم إعدادها لذلك. צ. إستمارة تقويم طالبات التدريب الميدانى : تم إعداد إستمارة (تصميم الباحثون) تحتوى على المحاور والعبارات التى تدور حول مكونات درس التربية الرياضية والمهارات التدريسية الخاصة بتنفيذ الدرس . خطوات تصميم الاستمارة: قام الباحثون بالإجراءات الأتية لتصميم الاستمارة : أ- الاجراءات التمهيدية لبناء إستمارة التقويم : - - تم الاطلاع على أغلب إستمارات تقويم طالبات التدريب الميدانى وذلك لحصر محاور وعبارات إستمارة تقويم طالبة التندريب الميدانى فى تتفيذ وإدارة درس التربية الرياضية. - - تم عمل دراسة للأبحاث والمراجع العلمية التى تتاولت تقويم درس التربية الرياضية.

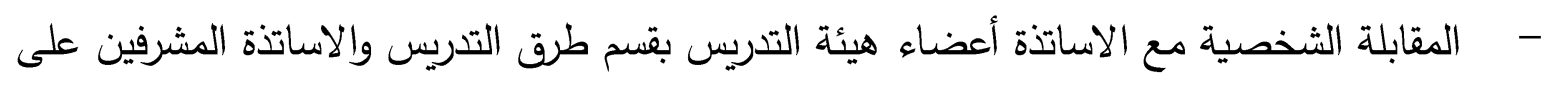
توجية الطالبات فى التدريب الميدانى ، وذلك بغرض جمع بيانات يمكن الاستعانة بها فى تحديد

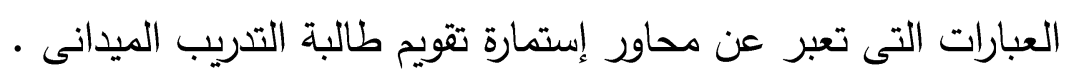
ب-الإجراءات الأساسية لبناء إستمارة التقويم : من خلال القراءات النظرية والمقابلات الثخصية قام الباحثون بعمل الاتى: - - التربية العملية وخاصة المهارات التى ترتبط بتنفيذ وتقويم أجزاء الدرس. - م وضع عبارات تقابل محتوى الاستمارة المقترحة حيث تقيس تلك العبارات المهارات التدريسية الخاصة تتفيذ درس التربية الرياضية . 
- - تم تحديد محاور إستمارة تقويم طالبات التدريب الميدانى فى تتفيذ درس التربية الرياضية وإشتملت على المهارات التدريسة الخاصة بالتنفيذ, وقد تكونت من (^ی عبارة ). تجربة البحث:

أولاً : الدراسة الإستطلاعية :

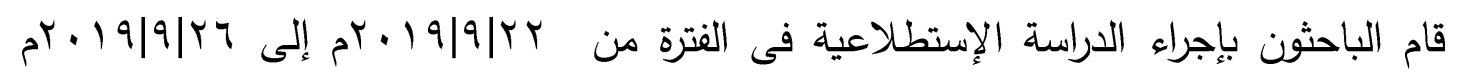
وذلك بغرض : n

ا. التغلب على بعض المعوقات المتعلقة بعملية تصوير الطلاب وإختبار أنسب أماكن

$$
\text { التصوير }
$$

r. التحقيق من سهولة إستخدام إستمارة التقويم ومناسبتها لتقويم طالبة التربية العملية . r. بعد إجراء الدراسة الإستطلاعيةالأولى والثانية قام الباحثون بالإستعانة بنموذج لحصة تربية رياضية وتم عرض حصة التربية الرياضية على المشرفين كخبراء ، وذلك لعرضهاعلى المجموعة التجريبية للوقوف على المهارات التدريسية المراد تعليمها وذلك قبل تطبيق تجربة

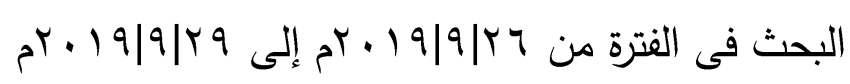

$$
\text { ثانياً: القياسات القبلية: }
$$

إستتاجاً على نتائج الدراسة الإستطلاعية التى قام بها الباحثون لإختيار مكان البحث والتأكد من توافر الإمكانيات المناسبة لتنفيذ التجربة والتأكد من صلاحية إستمارة التقويم للتطبيق ، قام الباحثون بإجراء القياسات القبلية لعينة البحث ، والتى تضمنت المجموعتين الضابطة والتجرببية حيث قامت الباحثونة بمناقشة وعرض محاور وعبارات إستمارة التقويم الخاصة بتنفيذ الدرس على جميع الطالبات ، وقام الباحثون بتكليف كل طالبة فى المجموعتين بتحضير نموذج كامل لدرس التربية الرياضية مدته

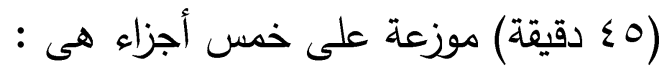

$$
\begin{aligned}
& \text { - - المقدمة والإحماء وزمنها مق } \\
& \text { - - الإعداد البدنى وزمنه ماق } \\
& \text { - - النشاط التعليمى وزمنه - اق } \\
& \text { - - النشاط التطبيقى وزمنه - - } \\
& \text { - - النشاط الختامى وزمنه مق لق }
\end{aligned}
$$


ثم قام الباحثون بإجراء القياسات القبلية للمجموعتين التجريبية والضابطة فى الفترة من

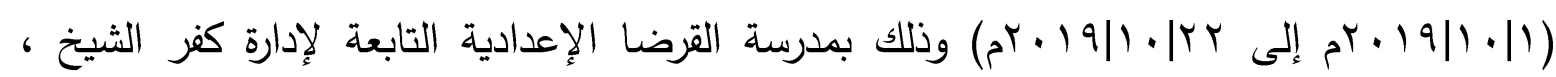
حيث تم تصوير درس واحد أعدته كل طالبة من طالبات المجموعتين كتابياً وتم تنفيذ أجزاء الدرس على طلاب المرحلة الإعدادية ، وقد تم تشكيل لجنه مكون من ثلاث مشرفين من مشرفين التدريب الميدانى لتقويم أداء الطالبات فى القياس القبلى. ثالثاً: تطبيق تجربة البحث:

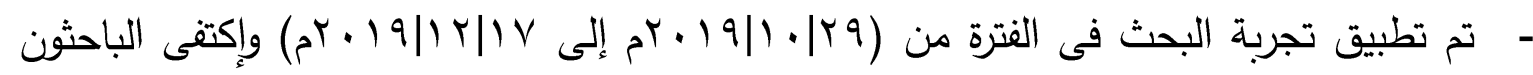
بإعطاء النقد الخاص بالمجموعة الضابطة طوال فترة التجربة كما فى الطريقة المتبعة . - تم عرض حصة نموذجية ثم عرضها على طالبات المجموعة التجريبية مع التأكيد على مهارات التدريس الخاصة بتنفيذ الدرس • - ثم قام الباحثون بتصوير أفراد المجموعة التجريبية أثناء تتفيذهم لأجزاء درس التربية الرياضية وذلك بمدرسة القرضا الإعدادية التابعة لإدارة كفر الثيخ ، حيث تم تتفيذ إجراءات الدراسة على طالبات المرحلة الإعدادية .

- ت تم تنفيذ أسلوب العمل بتقديم التغذية الراجعة بمعرفة الأداء من خلال التصوير وإعادة العرض على طالبات المجموعة التجريبية لكل جزء من أجزاء الدرس ( المقدمة والإحماء - الإعداد البدنى - النشاط التعليمى - النشاط التطبيقى - النشاط الختامى ) مع توفير النقد المتعلق بالأداء كتابياً وشفهياً وأيضًا قام الباحثون بإستخدام برنامج Whats app كنوع من أنواع التعلم النقال وقام الباحثون بإنشاء مجموعة علية مكونه من عينة البحث (طالبات التدريب الميدانى) ومشرفين التدريب الميدانى وعن طريق هذه المجموعة تم إرسال الفيديوهات المصوره للطالبات - وتم تبادل النقد المتعلق بأداء كل طالبة مع إعادة العرض ثم فى النهاية تم تصوير درس كامل لكل طالبة من طالبات المجموعة التجريبية وعرض الدرس عليهم ، سيتم تقسيم المجموعتين

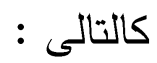
1- المجموعة التجريبية (1- (1) r 
تم تنفيذ أسلوب النقد المتعلق بالآداء كتابيا وشفهيا للمجموعة الضابطة وكما فى الطريقة المتبعة وذلك بمدرسة الحمراوى الإعدادية التابعة لإدارة كفر الشيخ ، على طالبات المرحلة الإعدادية بالمدرسة ، وكان العمل للمجموعتين أثناء اليوم المخصص للتربية العملية وهو يوم الثلاثاء من كل أسبوع.

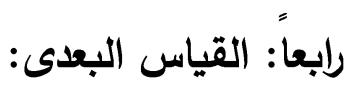

تم اجراء القياس البعدى على مجموعتى البحث التجريبية والضابطة بعد الانتهاء من تطبيق

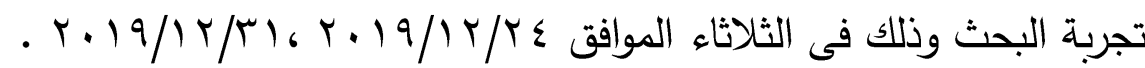

المعالجات الاحصائية :

اعتمد الباحثون على الاساليب الاحصائية الملائمة لتطبيق البحث وهدفة فى معالجة البيانات احصائيا وكانت الاساليب الاحصائية المستخدمة هى : - - المتوسط الحسابى.

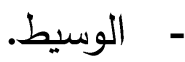
- الانحراف المعيارى - معامل الالتواء -

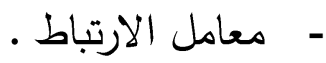
- اختبار (ت) لايجاد معامل الصدق. - مسبة التحسين - تحليل التباين -

- معنوية الفروق باستخدام اقل فرق معنوى معD عرض النتائج ومناقشتها: وبعد الإنتهاء من التطبيق قام الباحثون بقياس الفروق بين القياس القبلى والبعدى لكل من المجموعة التجريبية والضابطة وعرض النتائج كالأتى: 


\section{جدول(1)}

دلالة القروق بين القياس القبلي والبعدى لاى مجموعة|لبحث التجريبية فى عبارات المحور الثانى الخاص بالتنفيذ

\begin{tabular}{|c|c|c|c|c|c|c|c|c|c|}
\hline \multirow{2}{*}{ نسب معدل } & \multirow{2}{*}{ قيمة ت } & \multirow{2}{*}{ المعياري } & \multirow{2}{*}{ فروق } & \multicolumn{2}{|c|}{ القياس البعدى } & \multicolumn{2}{|c|}{ القياس القبلي } & \multirow{2}{*}{ العبار ات } & \\
\hline & & & & $\varepsilon \pm$ & س & $\varepsilon \pm$ & س & & \\
\hline$\vee 9,7 \vee 1$ & $0, r \leq \varepsilon$ & $\cdot, r \cdot r$ & $1, \cdot 17$ & $\cdot, \leqslant \leqslant V$ & $r, \leqslant 0$. &., 0.0 & & تتفئذ الأحمــاء بمـا يـؤدي الـي & 1 \\
\hline $1.7, \vee \wedge 9$ & $7, \ldots \varepsilon$ & • & $1, r \circ 9$ & r. & rT, & $\cdot, \leqslant 7 \vee$ & $1, Y V T$ & التمرينات اعـاه شـرح ونوضـيح أداء & r \\
\hline$V T, \ldots$ & $\varepsilon, \cdot r_{0}$ & $\cdot, r \leqslant V$ & - ,997 & $\cdot, v \cdot 1$ & $r, r \circ q$ &., 0.0 & & 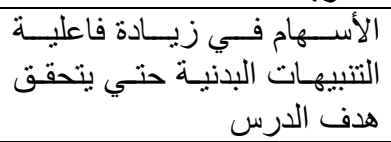 & r \\
\hline$V \varepsilon, 79 r$ & $0, r \leq \varepsilon$ & $\cdot, r \cdot r$ & $1, \cdot 17$ & $\cdot, r \cdot r$ & $Y, 0 \leq 1$ & - ,OY & $1, \leqslant 00$ & النيتـــار المكــان الصــحيح لأداء & $\varepsilon$ \\
\hline $99,7 \vee$. & $0, \Sigma Y T$ & $\cdot, Y 01$ & $1, r \circ 9$ & $\cdot, \vee \wedge \wedge 7$ & $r, V Y T$ &., 0.0 & צ 1 וד & 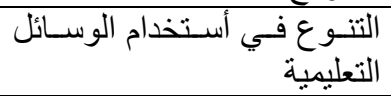 & 0 \\
\hline$\wedge V, 191$ & $\varepsilon, \Lambda \backslash \Gamma$ & אדצ, • & $1, r>1$ & $\cdot, \leqslant 7 V$ & Y,VYT & - OYY & $1, \leqslant 00$ & 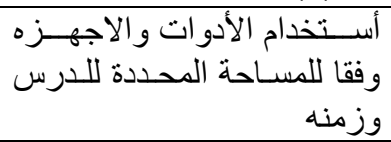 & 7 \\
\hline גזr, & $\varepsilon, M I V$ & $\cdot, T V T$ & $1, I V V$ & $\cdot, v \cdot 1$ & $r, 0 \leq 1$ &., 0.0 & & ور السلام أثناء أدير عـاء التلاميذ الأمسن & V \\
\hline$q q, \cdot V r$ & $\varepsilon, O \vee T$ & • & $1, \leq \varepsilon 1$ & .,OYT & $r, \wedge 97$ & .,OYT & $1, \leqslant 00$ & 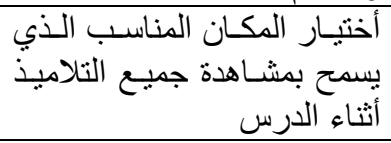 & $\wedge$ \\
\hline$\| r, r \leqslant r$ & $T, \leqslant T Y$ & • & 1,OK & •,OYY & $r, \wedge 97$ &., 0.0 & & مر التلاميذ اة الفـروق الفرديـة لـدي & 9 \\
\hline $1.7, \vee \wedge 9$ & T & $\cdot, Y)$ & $1, r \circ 9$ & $\cdot, \varepsilon, 0$ & rT, & $\cdot, \leqslant 7 V$ & $1, r V T$ & 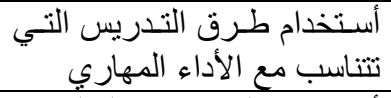 & 1. \\
\hline$V \varepsilon, 79 r$ & $V, 1 \leq r$ & $\cdot, 10 r$ & $1, \cdot 17$ & $\cdot r \cdot r$ & $Y, 0 \leq 1$ & .,OYY & $1, \leqslant 00$ & 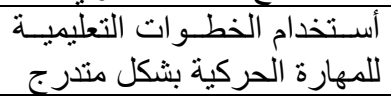 & 11 \\
\hline$q 9,7 \vee$. & $0, \Sigma Y T$ & $\cdot, r 01$ & $1, r \circ 9$ & $\cdot, \leqslant 7 V$ & Y,VYT &., 0.0 & & أستخدام عبار ات لفظية تلناسـب السنيه للتلاميذ & IT \\
\hline$q \Gamma, \ldots \varepsilon$ & $7,0 . \leqslant$ & $\cdot, 190$ & $1, r \backslash 1$ & $\cdot, 101$ & rTr, &., 0.0 & ع 1,1 & 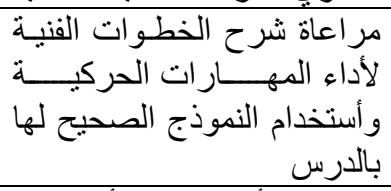 & سו \\
\hline NV, ro. & $7,7 \leq 1$ & $\cdot, r \cdot r$ & 1, & .,OYT & $r, \wedge 97$ & - OYT & $1,0 \leq 7$ & الصر اعــــاة أســـتخدام الأســلـوب & $1 \varepsilon$ \\
\hline $99,7 \vee$. & $0, \Sigma Y T$ & $\cdot, r 01$ & $1, r \circ 9$ & $\cdot, \leqslant 7 V$ & r,VYr & $\cdot, 0.0$ & צ & 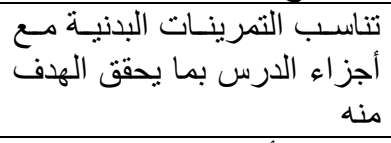 & 10 \\
\hline$\Lambda \cdot, 9 \leq r$ & $\Lambda, r \circ q$ & $\cdot, 1 \leq 1$ & $1, I V V$ & $\cdot, 101$ & $r, T r r$ & . OY & $1, \leqslant 00$ & 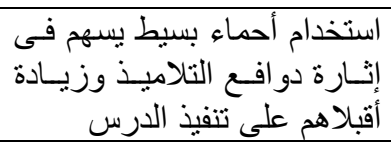 & 17 \\
\hline
\end{tabular}




\begin{tabular}{|c|c|c|c|c|c|c|c|c|c|}
\hline \multicolumn{3}{|c|}{ آسمد آول } & \multicolumn{5}{|c|}{ الهبحلة الصلهية لملىم الرياخة } & \multicolumn{2}{|l|}{ يعضيو - P P } \\
\hline 人T, & $\varepsilon, \mu \backslash V$ & • & $1,1 \vee V$ & $\cdot, V \cdot 1$ & $r, 0 \leqslant 1$ & $\cdot, 0.0$ & 1, & 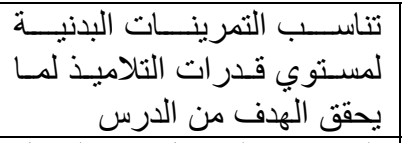 & iv \\
\hline $7 \Lambda, \varepsilon \leqslant r$ & $\varepsilon, \cdot r_{0}$ & $\cdot, r \leqslant V$ & $\cdot, 997$ & 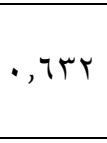 & $r, \varepsilon 0$. & $\cdot$, OY & $1, \leqslant 00$ & 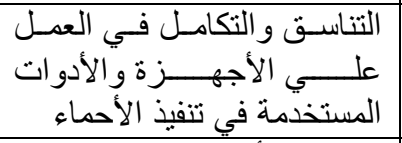 & 11 \\
\hline Irr, $79 \varepsilon$ & $0, r V V$ & $\cdot, Y V \cdot$ & $1, \leqslant 0$. & $\cdot, \vee 01$ & r & $\cdot, \varepsilon \cdot 0$ & $1,1 \wedge r$ & 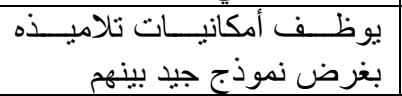 & 19 \\
\hline$q \pi, \ldots \varepsilon$ & $9, \ldots 0$ & $\cdot, 1 \leq 1$ & $1, Y \backslash \wedge$ & $\cdot, \vee 01$ & ( &., 0.0 & 1, 1, & 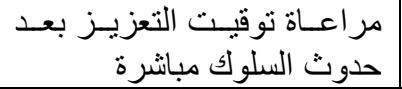 & r. \\
\hline AV, ro. & $0, \leqslant 09$ & $\cdot, r \leq V$ & 1, ro. & $\cdot$, OY & $r, \wedge 97$ & $\cdot$, OY & $1,0 \leqslant 7$ & للتدريب علامي القيادة والتادة التابعية لتلاميذ & r) \\
\hline 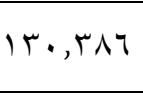 & $1 \cdot, 1 \Gamma$ & $\cdot, 10 Y$ & $1,0 \leqslant 1$ & $\cdot, \leqslant T V$ & Y,VYT & $\cdot, \varepsilon \cdot 0$ & $1,1 \wedge r$ & 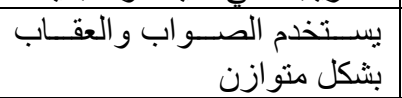 & rt \\
\hline$\Lambda \cdot, 9 \leq r$ & $\varepsilon, M I V$ & $\cdot, Y V T$ & $1, I V V$ & $\cdot, 7 \cdot r$ & r,TrY & $\cdot$, OYY & $1, \leqslant 00$ & الثناء علي الاداء الجيد & r \\
\hline IrT, T9 & $0, T \vee V$ & $\cdot, Y V \cdot$ & $1, \leqslant 0$. & $\cdot, \vee 01$ & ( & $\cdot, \varepsilon \cdot 0$ & $1,1 \wedge r$ & لتثبيث الأداء التكرار بطريقة مشوقه & $r \varepsilon$ \\
\hline$\vee 9,7 \vee 1$ & $\Gamma, \wedge 9 \wedge$ & $\cdot, r \vee q$ & $1, .17$ & $\cdot, \vee \vee 0$ & $r, \varepsilon 0$. &., 0.0 & ع 1,1 & 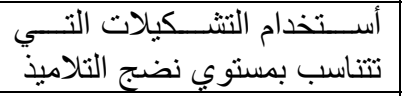 & ro \\
\hline$V q, q \leq r$ & $0,17 r$ & $\cdot, r \leqslant \varepsilon$ & $1, r \circ 9$ & •, OY & $r, \wedge 97$ & $\cdot, 0.0$ & דוד 1, & 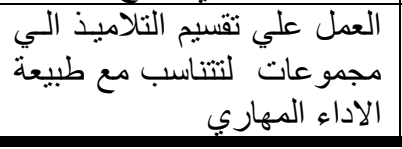 & rT \\
\hline$q 1, V \backslash V$ & $1 V, \varepsilon \leq 7$ & $1, \lambda 94$ & 11 & $\varepsilon, \wedge 99$ & $79, \cdot 11$ & $\Gamma, \wedge 9 q$ & $r 4, \ldots$ & المجموع & \\
\hline
\end{tabular}

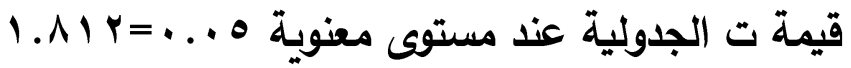

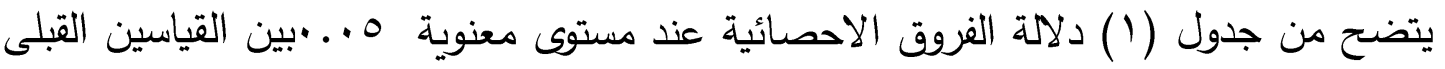

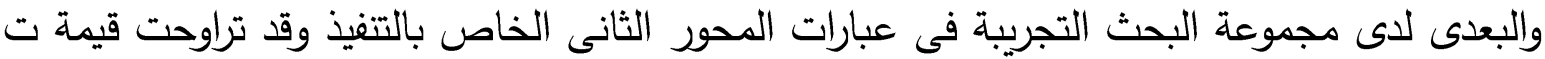

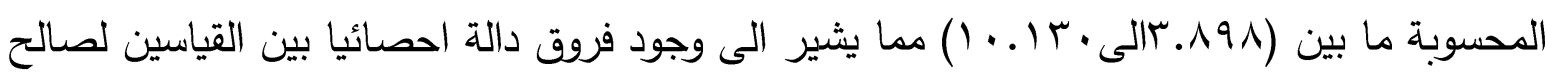

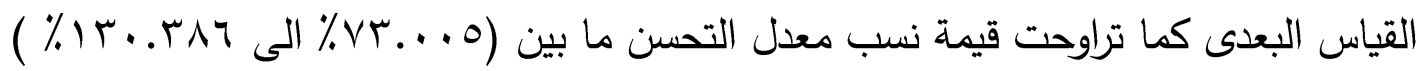

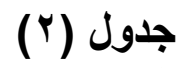

دلالة الفروق بين القياس القبلي والبعدى لاى مجموعة البحث التجريبية فى محاور واجمالى التى مقياس مستوى أداء مهارة التنفيذ

\begin{tabular}{|c|c|c|c|c|c|c|c|c|c|}
\hline \multirow{2}{*}{ نسب معدل } & \multirow{2}{*}{ قيمة ت } & \multirow{2}{*}{ اللمتوسيارً } & \multirow{2}{*}{ المتوسطا } & \multicolumn{2}{|c|}{ القياس البعدى } & \multicolumn{2}{|c|}{ القياس القبلي } & \multirow{2}{*}{ المحاور } & \multirow[b]{2}{*}{ r } \\
\hline & & & & $\varepsilon \pm$ & س س & $\varepsilon \pm$ & س س & & \\
\hline$q 1, V) \vee$ & $V, \varepsilon \leqslant 7$ & $1, \wedge 94$ & גון,עr & $\Sigma, \wedge ৭ q$ & $79, .11$ & $\Gamma, \wedge ৭ q$ & . . & التنفيذ & 1 \\
\hline
\end{tabular}

\section{قيمة ت الجدولية عند مستوى معنوية ه ... = Y I. 1.}

يتضح من جدول (Y) دلالة الفروق الاحصائية عند مستوى معنوية ه ه. . بين القياسين القبلى

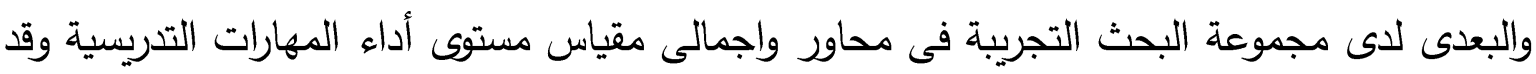

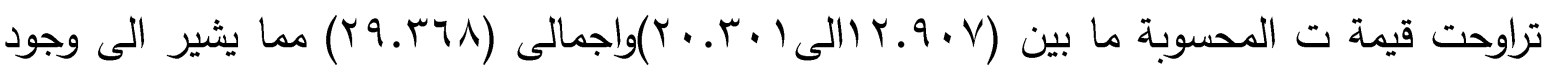


فروق دالة احصائيا بين القياسين لصالح القياس البعدى كما تراوحت قيمة نسب معدل التحسن ما بين

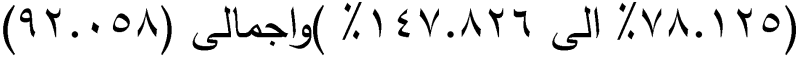

$$
\begin{aligned}
& \text { جدول(r) }
\end{aligned}
$$

معنوية حجم التأثير لمحور واجمالى مقياس مستوى أداء مهارة التفيذ لاى مجموعة البحث التجريبية وفقا لمعادلات كوهن

$11=\dot{0}$

\begin{tabular}{|c|c|c|c|c|c|c|}
\hline دلالة حجم & التأثخير & ايتاب & مستوى الدلاية & قيمة (ت) & القياس & المحاور الالالات الإحصائية \\
\hline مرتفع & $r, r \wedge I$ & 0,970 & $\cdot, \ldots$ & $1 V, \leqslant \leq 7$ & درجة & التنفيذ \\
\hline
\end{tabular}

يتضح من جدول (r) ان قيم حجم التاثير لمحاور واجمالى مقياس مستوى أداء المهارات

التدريسية لدى مجموعة البحث التجريبية قد حققت قيمة قدرها (IN.M) وهى داله مرتفعة مما يدل

على فاعلية البرنامج بشكل قوى على المتغير التابع

\section{جدول (ع )}

دلالة الفروق بين القياس القبلي والبعدى لاى مجموعة البحث الضابطة فى العبارات الخاص بمحور التنفيذ

$11=ن$

\begin{tabular}{|c|c|c|c|c|c|c|c|c|c|}
\hline \multirow{2}{*}{ 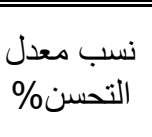 } & \multirow{2}{*}{ قيمة ت } & \multirow{2}{*}{ المعيارئ } & \multirow{2}{*}{ المنوسطات } & \multicolumn{2}{|c|}{ القياس البعدى } & \multicolumn{2}{|c|}{ القياس القبلي } & \multirow{2}{*}{ العبار ات } & \multirow{2}{*}{ r } \\
\hline & & & & $\varepsilon \pm$ & س & $\varepsilon \pm$ & س س & & \\
\hline$r v, 0 \ldots$ & 1, & $\cdot, Y \wedge T$ & $\cdot, 0 \leq 0$ & - , TV0 & $r, \ldots$ & •,OYT & $1, \leqslant 00$ & تتفيئه الأحمـاء بــا يـؤديذ الي & 1 \\
\hline סזr, & $1,97 r$ & • & $\cdot, \leqslant 00$ & $\cdot, \vee \vee \leqslant \varepsilon$ & $1, \wedge) \wedge$ & $\cdot, 0.0$ & ع & التمرينات شــرح وتوضـيح أداء & r \\
\hline ro, & $1, \wedge \neg \varepsilon$ & $\cdot, r \leq \varepsilon$ & $\cdot, \leqslant 00$ & $\cdot, 7 \wedge 7$ & $1, V Y V$ & $\cdot, \leqslant 7 V$ & $1, Y \vee T$ & 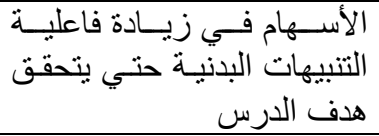 & r \\
\hline 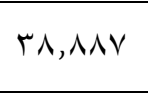 & $r, r \wedge r$ & $\cdot, r \vee q$ & צדוד י & $\cdot, 0 \leqslant V$ & $r, r V T$ & $\cdot, 0.0$ & דודות & النموذجـار المكـان الصـحيح لأداء & $\varepsilon$ \\
\hline rᄉ, $\leqslant 70$ & $1, \wedge \backslash \leq$ & $\cdot, r \leq \varepsilon$ & $\cdot, \leqslant 00$ & $\cdot, \varepsilon, 0$ & דזד, 1 & $\cdot, \leqslant .0$ & $1,1 \wedge r$ & التعليمية في أسـتخدام الوســائل & 0 \\
\hline$r v, 0 \ldots$ & 1, & $\cdot, Y \wedge T$ & $\cdot, 0 \leq 0$ & $\cdot, 7 \vee 0$ & $r, \ldots$ & .,OYT & $1, \leqslant 00$ & 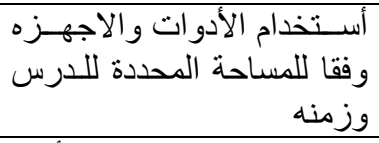 & 7 \\
\hline$r \cdot, . . r$ & $1, q \mu v$ & $\cdot, 1 \leq 1$ & $\cdot, r V T$ & $\cdot, \varepsilon .0$ & דזד, 1 & $\cdot, 0.0$ & 1, & 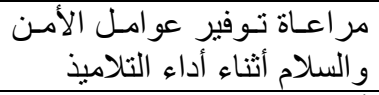 & V \\
\hline 11, VOr & דיד,r & •, Irr & $\cdot, Y V T$ & $\cdot, 7 \wedge 7$ & $1, V Y V$ & $\cdot, O Y Y$ & $1, \leqslant 00$ & 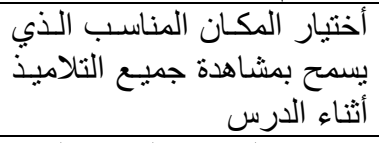 & $\Lambda$ \\
\hline$r r, \cdot V r$ & 1,947 & $\cdot, 1 \leq 1$ & • , YVT & $\cdot, \Sigma Y r$ & $1, \leqslant 00$ & $\cdot, \varepsilon \cdot 0$ & $1,1 \wedge r$ & مراعلامبذ الفـروق الفرديـة لـدي & 9 \\
\hline סזr, זr & דוז, & $\cdot, r \cdot r$ & $\cdot, \leqslant 00$ & $\cdot, \vee \vee \varepsilon$ & $1, \wedge 1 \wedge$ & $\cdot, 0.0$ & ع 1 וד & تأستخدام طرق التدريس التهي & 1 . \\
\hline
\end{tabular}




\begin{tabular}{|c|c|c|c|c|c|c|c|c|c|}
\hline \multicolumn{3}{|c|}{ المده آ'ول } & \multicolumn{5}{|c|}{ الهمبحة الماهية لملىم الىيلغة } & \multicolumn{2}{|l|}{ 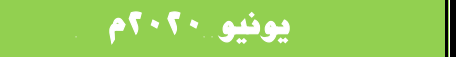 } \\
\hline$r V, V V V$ & Tr, & $\cdot, r \cdot r$ & $\cdot, £ 00$ & $\cdot, 7 \cdot 1$ & $r, .91$ &., 0.0 & דזדר & 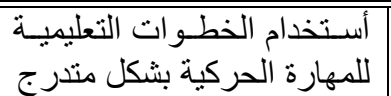 & 11 \\
\hline ץ,$\leqslant\rceil 0$ & 1, & $\cdot, r \leq V$ & $\cdot, \leqslant 00$ & $\cdot, \varepsilon \cdot 0$ & דזד, 1 & $\cdot, \varepsilon \cdot 0$ & $1,1 \wedge r$ & 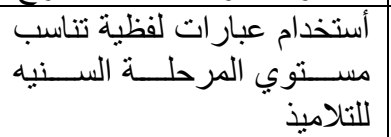 & IT \\
\hline$\varepsilon \cdot, \ldots 1$ & $r, r \cdot T$ & $\cdot, r \leq V$ & $\cdot, 0 \leqslant 0$ & $\cdot, \wedge \leq \varepsilon$ & $1,9 \cdot 9$ & $\cdot, 0.0$ & $1,1, \pi \leq$ & 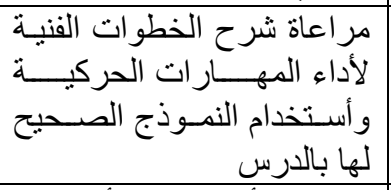 & Tr \\
\hline$r V, V V V$ & r, rTr & $\cdot, r \cdot r$ & $\cdot, \leqslant 00$ & $\cdot, 7 \cdot 1$ & $r, 91$ &., 0.0 & 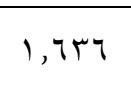 & مر اعــاة أســتخدام الأســلـوب للنداء & $1 \varepsilon$ \\
\hline$\varepsilon \cdot, \ldots 1$ & $1,9 \pi v$ & $\cdot, r \wedge r$ &, $0 \leqslant 0$ & $\cdot, V M I$ & $1,9.9$ &., 0.0 & 1, & 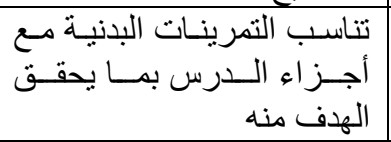 & 10 \\
\hline סשז,זr & 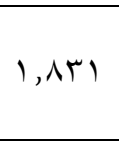 & $\cdot, r \vee q$ & $\cdot, \leqslant 00$ & $\cdot, \vee \vee \varepsilon$ & $1, \wedge) \wedge$ &., 0.0 & ع 1,1 & 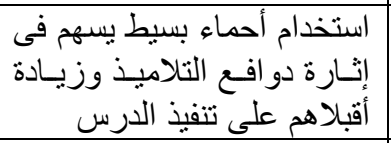 & 17 \\
\hline$\varepsilon \cdot, \ldots 1$ & $1,90 \mathrm{~V}$ & $\cdot, r \vee q$ & $\cdot, 0 \leq 0$ & $\cdot$, OH & $1,9 \cdot 9$ &., 0.0 & & 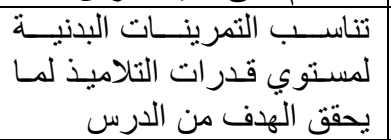 & IV \\
\hline TI, Y01 & 1, גז & $\cdot, r \leq V$ & $\cdot, \leqslant 00$ & ודז, • & $1,9 \cdot 9$ & $\cdot$, OY & $1, \leqslant 00$ & 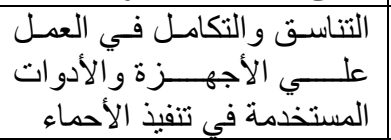 & 11 \\
\hline$r_{\Lambda}, \leqslant 70$ & l, גז & $\cdot, r \leqslant V$ & $\cdot, \leqslant 00$ & $\cdot, \lambda r \leq$ & דזד, 1י & $\cdot, \varepsilon .0$ & $1,1 \wedge r$ & 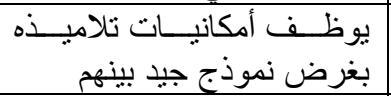 & 19 \\
\hline$\varepsilon \cdot, \ldots l$ & $r, Y \cdot T$ & $\cdot, r \leq V$ &., $0 \leqslant 0$ & $\cdot, V T_{1}$ & $1,9.9$ &., 0.0 & 1, & 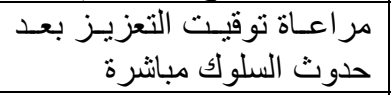 & $r$. \\
\hline$Y V, V V V$ & T, & $\cdot, r \cdot r$ & $\cdot, \leqslant 00$ & $\cdot, 7 \cdot 1$ & $r, .91$ &., 0.0 & דוזד 1, & 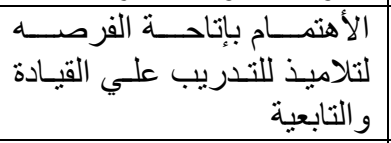 & YI \\
\hline r7, 779 & $1,9 \leq r$ & $\cdot, 1 \wedge \vee$ & ( & $\cdot, 7 \wedge 7$ & $1, V Y V$ &., 0.0 & ع 1 1, & 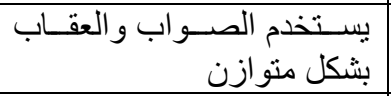 & rr \\
\hline YA,OVE & אחז,1 & $\cdot, Y V T$ & & $\cdot, \wedge Y \leq$ & וצד 1, & $\cdot, \Sigma T V$ & $1, Y \vee M$ & الثناء علي الاداء الجيد & r \\
\hline סשז, & 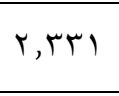 & $\cdot, 190$ & $\cdot, \leqslant 00$ & $\cdot, \vee \vee \leq$ & $1, \lambda 1 \wedge$ & $\cdot, 0.0$ & 1, & 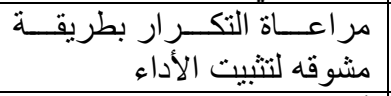 & $r \varepsilon$ \\
\hline rA, $\leqslant 70$ & l, & $\cdot, r \leq V$ & $\cdot, \leqslant 00$ & $\cdot, \lambda r \leq$ & 1, 1, 1, & $\cdot, \varepsilon .0$ & $1,1 \wedge r$ & 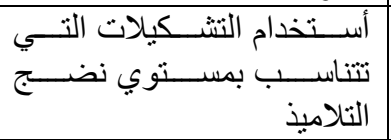 & ro \\
\hline$r v, 0 \ldots$ & (וT, & $\cdot, Y \cdot V$ & $\cdot, 0 \leqslant 0$ & $\cdot$, TVO & $r, \ldots$ & $\cdot$, orr & $1, \leqslant 00$ & 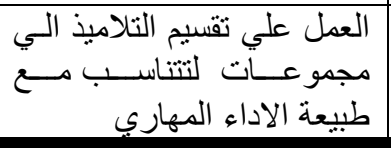 & rt \\
\hline$r \mu, 170$ & $\varepsilon, \cdot I V$ & T,970 & $11,9 \cdot 9$ & $1 \cdot 1 \cdot 1$ & $\varepsilon V, \wedge 1 q$ & $\overline{r, T V T}$ & $10,9.9$ & المجموع & \\
\hline
\end{tabular}

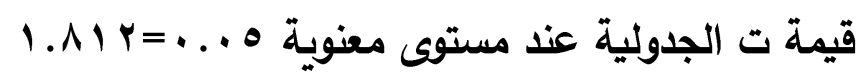

يتضح من جدول (ع) دلالة الفروق الاحصائية عند مستوى معنوية 0 . •بين القياسين القبلى

والبعدى لدى مجموعة البحث الضابطة فى عبارات المحور الثانى الخاص بالتتفيذ وقد تراوحت قيمة ت

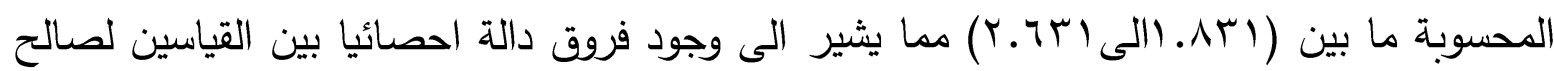

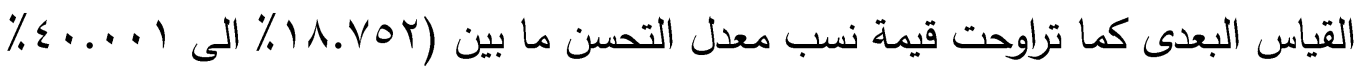




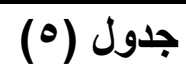

معنوية حجم التأثثر لمحور واجمالى مقياس مستوى أداء مهارة التنفيذ لاى مجموعة البحث الضابطة وفقا لمعادلات كوهن

$11=\dot{0}$

\begin{tabular}{|c|c|c|c|c|c|c|}
\hline دلالة حجم & التأثنير & معامل & مستوى & قيمة (ت) & والقباس & المحاور \\
\hline منخفض & ז & $\begin{array}{c}., 09 \\
0\end{array}$ & $\cdot, \ldots 1$ & $\varepsilon,+1 V$ & درجة & التنفيذ \\
\hline
\end{tabular}

يتضح من جدول (0) ان قيم حجم التاثير لمحاور واجمالى مقياس مستوى أداء المهارات

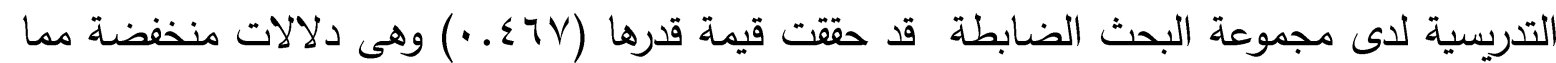

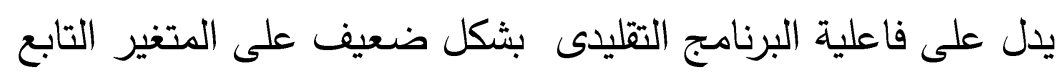

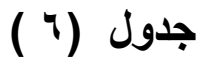

دلالة الفروق بين القياسات البعدية لدى مجموعتى البحث التجريبية والضابطة فى عبارات محور التنفيذ

$11=r ن=10$

\begin{tabular}{|c|c|c|c|c|c|c|c|c|}
\hline \multirow{2}{*}{ فروق نسب التحس\% } & \multirow[b]{2}{*}{ قيمة ت } & \multirow{2}{*}{ المنوسطات } & \multicolumn{2}{|c|}{ المجمو عة الضابطة } & \multicolumn{2}{|c|}{ المجمو عة التجريبية } & \multirow{2}{*}{ العبار ات } & \multirow{2}{*}{ م } \\
\hline & & & $\varepsilon \pm$ & س س & $\varepsilon^{ \pm}$ & س & & \\
\hline$\{r,|V|$ & $1,90 \leqslant$ & $\cdot, \leq 0$. & $\cdot$, TVo & $r, \ldots$ & $\cdot, \varepsilon \leqslant V$ & $r, \varepsilon 0$. & تتنفيذ الأحماء بما يؤدي الي تهيئه & 1 \\
\hline$V T, \leqslant 0 \leqslant$ & $r, \wedge \leq T$ & $\cdot, \lambda) \leq$ & $\cdot, V \vee \leq$ & $1, \wedge) \wedge$ & $\cdot, 7 \cdot r$ & r, & 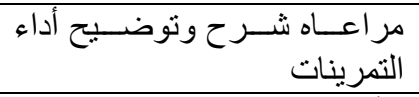 & r \\
\hline rV, r^q & $r, 1 \wedge V$ & י & • & $1, V Y V$ & $\cdot, V \cdot 1$ & $r, r \circ q$ & 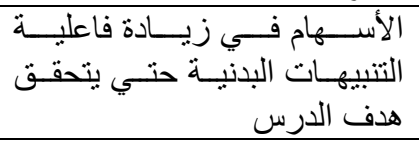 & r \\
\hline ro, A. . & $r, 10 \mathrm{~V}$ & • ג & $\cdot, 0 \leq V$ & $r, I V T$ & $\cdot, r \cdot r$ & $r, 0 \leqslant 1$ & النموذجـار المكــان الصــحيح لأداء & $\varepsilon$ \\
\hline $7, Y, 0$ & $\varepsilon, \cdot V V$ & $1, \cdot \wedge v$ & $\cdot, \varepsilon, 0$ & דוד 1, & $\cdot$, VАт & Y,VYT & التعليمية ع فـي أسـتـذام الوســائل & 0 \\
\hline$\leq 9,791$ & $r, \cdot 14$ & $\cdot, V Y T$ & $\cdot$, TVO & $r, \ldots$ & $\cdot, \leqslant 7 V$ & $r, V Y T$ & 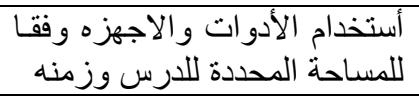 & 7 \\
\hline ס סTו, & $r, v \leq \varepsilon$ & $\cdot, 9.0$ & $\cdot, \varepsilon .0$ & 1, 1, & $\cdot, v \cdot 1$ & $r, 0 \leqslant 1$ & 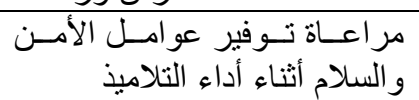 & v \\
\hline$\Lambda \cdot, r r$. & $\varepsilon, \vee \backslash$. & 1,179 & • & $1, V Y V$ & .,Orr & $r, \wedge 97$ & 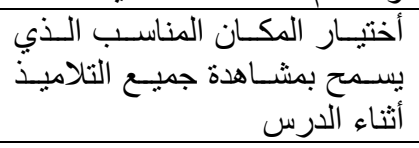 & $\wedge$ \\
\hline $19, r 79$ & $v, \varepsilon r$. & $1, \varepsilon \varepsilon 1$ & $\cdot, \varepsilon r r$ & $1, \leqslant 00$ & $\cdot$, OY & $r, \wedge 97$ & مر التلاميذ & 9 \\
\hline$V r, \leq 0 \leq$ & $r, r \vee \varepsilon$ & $\cdot, \Lambda) \leq$ & $\cdot, V \vee \varepsilon$ & $1, \lambda \backslash \wedge$ & $\cdot, \varepsilon .0$ & r,Trr & 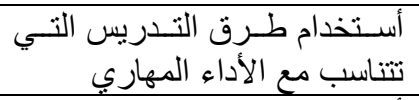 & 1 . \\
\hline$\leq 7,910$ & $r, \varepsilon r r$ & $\cdot, \leqslant 0$. & $\cdot, 7 \cdot 1$ & $r, .91$ & $\cdot, r \cdot r$ & $r, 0 \leqslant 1$ & 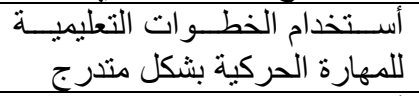 & 11 \\
\hline$T, Y, 0$ & זד דו, ד & $1, \cdot \wedge V$ & $\cdot, \leqslant .0$ & דוד, 1, & $\cdot, \leq 7 V$ & $r, V Y T$ & 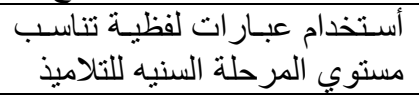 & IT \\
\hline
\end{tabular}




\begin{tabular}{|c|c|c|c|c|c|c|c|c|}
\hline \multicolumn{3}{|c|}{ آلمده آ'ول } & \multicolumn{4}{|c|}{ الهبماة آملهية لملوم الريانسة } & \multicolumn{2}{|l|}{ 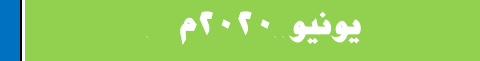 } \\
\hline or, ... & r, & $\cdot, V Y T$ & $\cdot, \lambda \leq \varepsilon$ & $1,9 \cdot 9$ & $\cdot, \vee 01$ & r, & 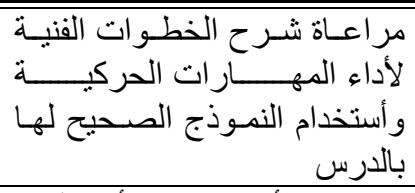 & Tr \\
\hline $09,0 \vee r$ & $r, 011$ & $\cdot, 1 \cdot 0$ & $\cdot, 7 \cdot 1$ & $r, .91$ & $\cdot$, OY & $r, \wedge 97$ & 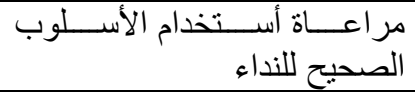 & $1 \varepsilon$ \\
\hline 09,779 & $r, r \vee q$ & $\cdot, \lambda) \leq$ & $\cdot, V(M)$ & $1,9 \cdot 9$ & $\cdot, \Sigma T V$ & $r, V Y T$ & 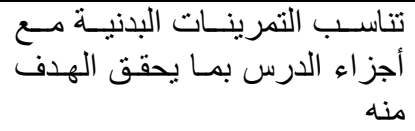 & 10 \\
\hline$\varepsilon V, T \cdot V$ & $r, 001$ & $\cdot, \lambda) \leq$ & $\cdot, \vee \vee \varepsilon$ & $1, \lambda \backslash \wedge$ & $\cdot, \vee 01$ & r, Trr & 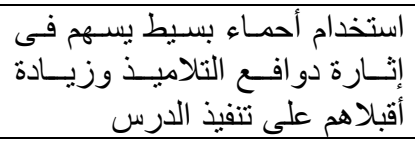 & 17 \\
\hline ET,TrV & $r, \leqslant r q$ & צזד, • & $\cdot, 041$ & $1,9 \cdot 9$ & $\cdot, v \cdot 1$ & $r, 0 \leqslant 1$ & 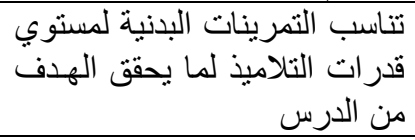 & IV \\
\hline$r v, 19 r$ & $r, \cdot v r$ & $\cdot, 0 \leq 1$ & וד, • & $1,9.9$ & צTT, • & $r, \leq 0$. & 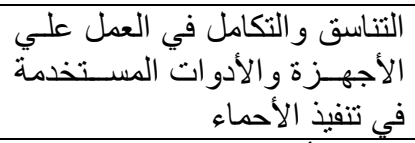 & 11 \\
\hline$\Lambda \varepsilon, Y r$. & $r, .19$ & $\cdot, 997$ & $\cdot, \lambda r \varepsilon$ & דוד, 1, & $\cdot, \times 01$ & r, Trr & نموذج جيد أمكانيات تلاميذه بغرض & 19 \\
\hline or,... r & r,TM & $\cdot, V Y T$ & $\cdot, V M I$ & $1,9.9$ & $\cdot, \vee 01$ & r,Tr & 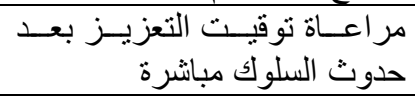 & $r$. \\
\hline $09,0 \vee r$ & $r, 011$ & $\cdot, 1 \cdot 0$ & $\cdot, 7 \cdot 1$ & $r, .91$ & .,OYT & $r, \wedge 97$ & 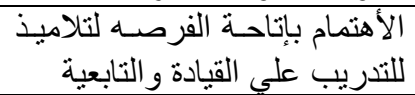 & YI \\
\hline $1 \cdot r, V \backslash V$ & $\varepsilon, Y \cdot r$ & $\cdot, 997$ & $\cdot, 7 \wedge 7$ & $1, V Y V$ & $\cdot, \Sigma T V$ & $r, V Y T$ & منوازندم الصو اب و العقاب بشـكل & $r r$ \\
\hline or, rד & $r, r \leq r$ & $\cdot, 997$ & $\cdot, \lambda Y \varepsilon$ & $1,7 \pi$ & $\cdot, 7 \cdot r$ & $r, T H Y$ & الثناء علي الاداء الجيد & $r r$ \\
\hline ^৭, זч. & $r, 001$ & $\cdot, \lambda) \leq$ & $\cdot, \vee \vee \varepsilon$ & $1, \lambda \backslash \wedge$ & $\cdot, \times 01$ & r & لتثبيت اعاة التـكراء ار بطريقـة مشـوقه & $r \leq$ \\
\hline$\varepsilon 1, r \cdot V$ & $r, \varepsilon r V$ & $\cdot, \lambda) \leq$ & $\cdot, \lambda r \varepsilon$ & דוזד, & $\cdot, \vee \vee 0$ & $r, \leqslant 0$. & أستتخدام التشكيلات التي نتتاسـب & ro \\
\hline rq, $\leqslant \leqslant r$ & $r, \tau \leqslant \Lambda$ & $\cdot, \wedge 97$ & $\cdot, 7 \vee 0$ & $r, \ldots$ & $\cdot$, Or & $r, \wedge 97$ & 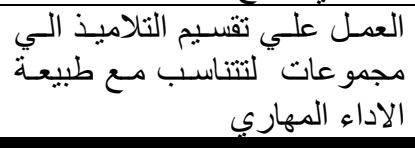 & ry \\
\hline $0 \Lambda, 00 Y$ & $7, \cdot 17$ & 1,199 & $1 \cdot, 1 \cdot 1$ & $\sum \vee, \wedge 19$ & $\varepsilon, \wedge 99$ & $79, .11$ & المجموع & \\
\hline
\end{tabular}

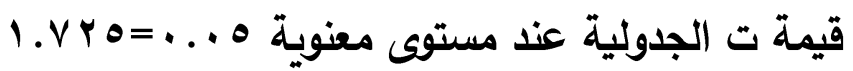

يتضح من جدول (T) دلالة الفروق الاحصائية عند مستوى معنوية ه م. •ببين القياسات البعدية

لاى مجموعتى البحث التجريبية والضابطة فى عبارات محور التنفيذ وقد تراوحت قيمة ت المحسوبة

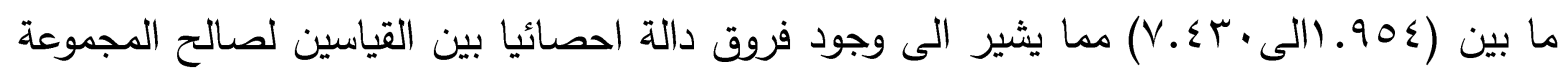

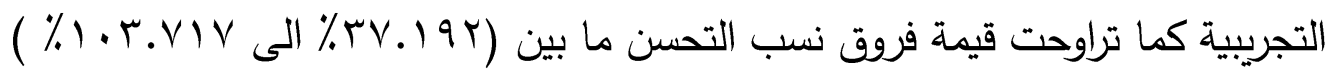




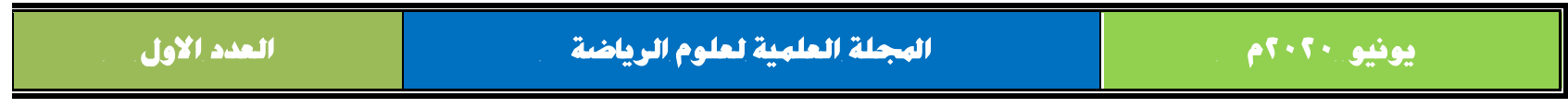

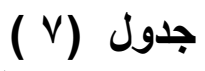

دلالة الفروق بين القياسات البعدية لدى مجموعثى البحث التجريبية و الضابطة فى محاور

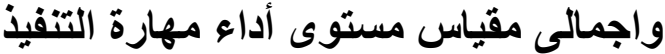

\begin{tabular}{|c|c|c|c|c|c|c|c|c|}
\hline \multirow{2}{*}{ فروق نسب } & \multirow[b]{2}{*}{ قيمة ت } & \multirow{2}{*}{ فروق } & \multicolumn{2}{|c|}{ المجمو عة الضـابطة } & \multicolumn{2}{|c|}{ المجمو عة التجريبية } & \multirow{2}{*}{ المحاور } & \multirow{2}{*}{ s } \\
\hline & & & $\varepsilon \pm$ & س & $\varepsilon \pm$ & س & & \\
\hline $0 \wedge, 00 Y$ & $7, \cdot 17$ & 41,199 & $\begin{array}{c}1 \cdot, 1 \\
\wedge\end{array}$ & $\begin{array}{c}\varepsilon V, \wedge 1 \\
q\end{array}$ & $\varepsilon, \wedge 99$ & $79, .11$ & التنفيذ & 1 \\
\hline
\end{tabular}

$$
\text { قيمة ت الجدولية عند مستوى معنوية ه ... }
$$

يتضح من جدول (V) دلالة الفروق الاحصائية عند مستوى معنوية ه ه..بين القياسات البعدية

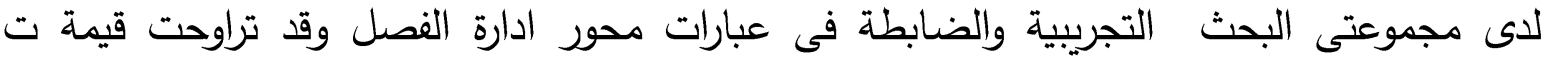

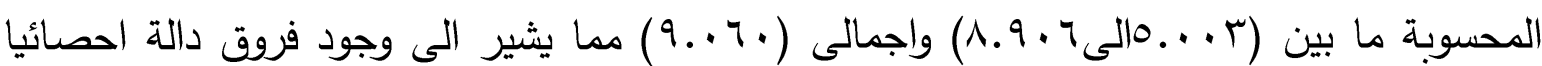

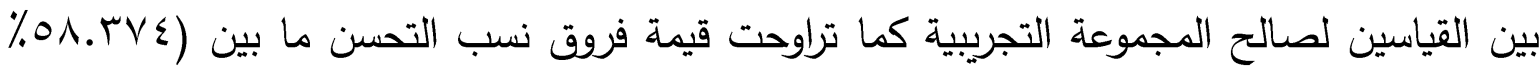

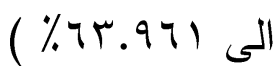

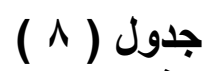

معنوية حجم التأثير لمقياس مهارة التنفيذ بين مجموعتى البحث التجريبية والضابطة وفقا

\begin{tabular}{|c|c|c|c|c|c|c|}
\hline دلالة حجم & التأثخر & ايتاب & مستوى & قيمة (ت) & القياس & المحاور اللالالات الإحصائية \\
\hline مرتفع & $r, . q V$ & . $7 \leqslant \varepsilon$ & 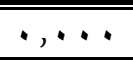 & $7, .17$ & لدرجة & التنفيذ \\
\hline
\end{tabular}

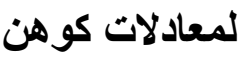

يتضح من جدول (^) ان قيم حجم التاثير لمقياس المهارات التدريسية بين مجموعتى البحث

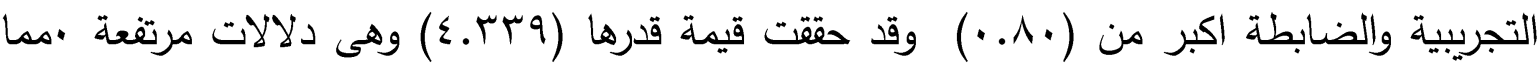
يذل على فاعلية البرنامج المقترح بشكل مرتفع على تلك المتغيرات لصالح المجموعة التجريبية عنة

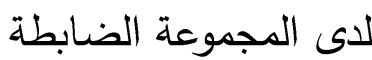
مناقشة النتائج: أولا: مناقثة نتائج الفرض الأول الذي ينص علي : توجد فروق ذات دلالة احصائية بين متوسطي القياسيين القبلي والبعدي للمجموعة التجريبية في متغير (التنفيذ) لصالح القياس البعدي. 
كما يتضح من جدول(1) ايضا وجود فروق ذات دلالة إحصائية عند مستوي معنوية ه . . بين القياسين القبلي والبعدي للمجموعة التجريبية فى عبارات المحور الثانى الخاص بالتنفيذ لصـالح

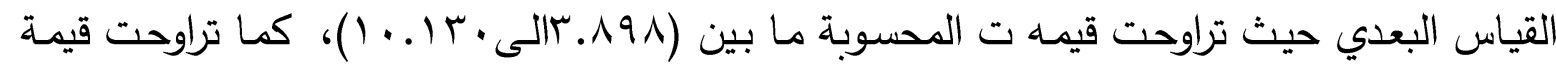

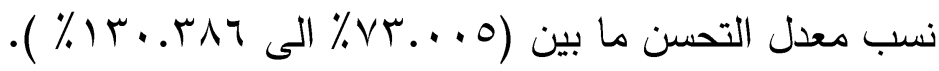
ويوضـح جدول (Y) وجود فروق ذات دلالة إحصـائية عند مستوي معنويـة ه . . بين القياسين القبلي والبعدي للمجموعـة التجريبية فـى محاورواجمالي مقياس مستوي أداء المهارة التنفيذ لصـالح

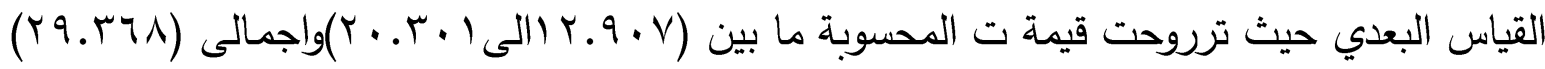

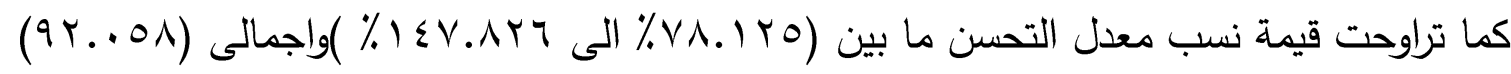
كما يتضح من جدول (r) أن قيم حجم التأثير لمحور واجمالى مقياس مستوى أداء مهارة التنفيذ قد حققت قيمـة أعلى مـن ( •^. • ) وهـى دلالـة مرتفعـة تشير إلى التأثير النسبى للمعالجـة التجربيـة

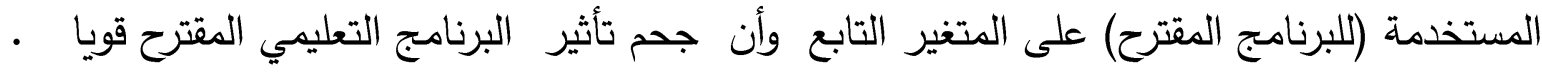
ويرجع الباحثون أن ما توصل إلية من نتائج ترجع إلي إنتظام أفراد المجموعة التجربيية في تنفيذ البرنامج المقترح بإستخدام التغذية الراجعة ،لما يحتوية البرنامج من عمليات اتصسال وتواصل بين الطالب و المعلومات المقدمة لهم من خلال معلومات عن طبيعة ادائة لمساعدته علي ادراك افضل للموقف التعليمي بالثكل الذي يساعدة في تحسين مستوي اداء المهارات التدريسية قيد البحث وذلك باستخدام الفيديووالتعلم النقال من خـلال الاجهزة الخلويـة (الجولات المحمولـة ) كمـا سـاعد ايضـا علي تكرار الاداء وبالتالي التمكن من تصحيح الاخطاء مماساعد علي تحديد الخطأ وتعيينة. ويعزو الباحثون هذا التحسن في مستوي اداء مهارة التنفيذ قيد البحث لدي افراد المجموعة التجريبيةالي ان عمليه التغذية الراجعة تقوم علي مجموعة من الاسس تعتمد علي كثف الاخطاء في الاداء ومحاولـة تصـحيحها مـن خـلال مشـاهدة النمـوذج والمقارنـة بينهمـا ممـا يؤدي الي تعزيز الاداء وتدعيم الاستجابات المتعلمة للطالب من خلال تغيير الاداء وتقديم المعلومات التي تساعد في تصحيح الاخطاء. وفي هذا الصـدد يشير سـميث دافيـا (991 199) التغذيـة الراجعـة هـى عمليـة ترتبط بعمليات الإتصـال والتواصـل , ومن خلالها يدرك الفرد أو الجماعـة نتائج إستجابتة أو نمط تلك الإستجابة , 
وتشير هذه العملية إلى المعلومات التى يتلقاها الفرد أو الجماعة عن ملائمة وكفاية أداتة , وكثيرا ما

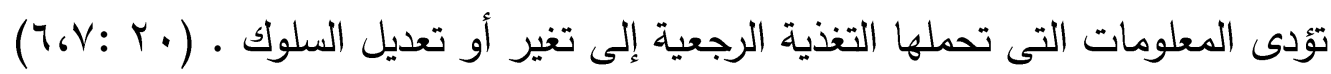
وتتفق نتائج البحث الحالي مع دراسة كلا من "هيزان تشون" و " هونجو لى " و" ديجونج كيم"

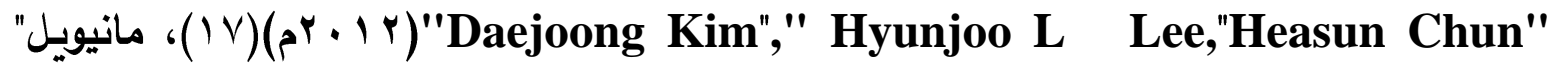
"Manuel"

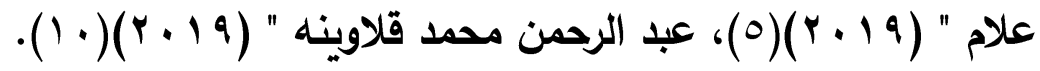
ومن خلال عرض ومناقشة وتفسير نتائج الفرض الأول يتضـح أنه قد تحقق إجرائيا من خلال

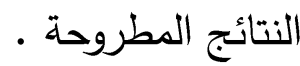
ثانياً: مناقشة نتائج الفرض الثاني والذي ينص علي: توجد فروق ذات دلالة احصائية بين متوسطي القياسيين القبلي والبعدي للمجموعة الضـابطة في متفيرات ( التفيذ) لصالح القياس البعدي.

ويوضـح جدول (ع) وجود فروق ذات دلالة إحصـائية عند مستوي معنوية ه . . ب بين القياسين القبلي والبعدي للمجموعة الضابطة فى محاورواجمالي مقياس مستوي أداء مهارة التنفيذ لصالح القياس

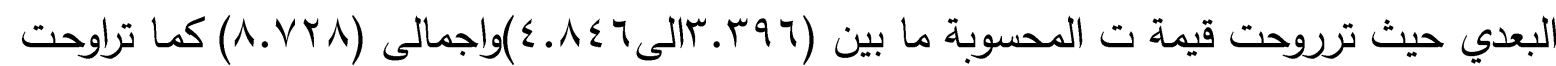

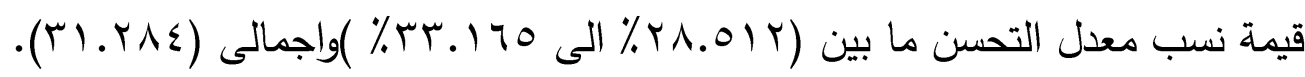
كما يتضح من جدول (0) أن قيم حجم التأثير لمحور واجمالى مقياس مستوى أداء مهارة التنفيذ

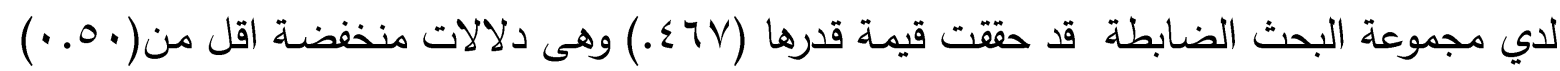
وهى دلالات منخفضة مما يدل على التاثير أو التحسن الضعيف للبرنامج التقليدي المتبع. ويرجع الباحثون ذلك التحسن إلي إنتظام أفراد المجموعة الضـابطة في تنفيذ البرنامج التعليمي التقليدى المتبع حيث يعد الإستمرار في التدريب والتعليم أحد المبادئ الأساسية في تتمية المعلومات والمعـارف والمهارات وهذا مـا أتقتت عليه معظم المراجع والدراسـات العلميـة في المجـالات التربويـة المختلفة . وفي ضوء ما سبق يري الباحثون أن إستخدام المجموعة الضـابطة وتطبيقها للبرنامج التقليدي من خلال (الثرح والإلقاء ) قد أثر إيجابيا علي متغيرات (تنفيذ) قيد البحث . 
ويعزو الباحثون ذلك التحسن إلى أن الطريقة التقليدية بإستخدام (الثرح والإلقاء ) قد أمدت الطلاب بالمعلومات والمعارف المرتبطة بمهارة( التنفيذ ) قيد البحث من خلال الإلقاء من قبل المعلم حيث يقوم المعلم بإعداد وتحضير الموقف التعليمي من خلال أسلوب الإلقاء أو المحاضرة أو الوصف أو العرض أوالتمثيل مما يبني فكرة عن موضوعات المقرر عند الطلاب وبالتالي يساعد علي إكتساب الأفكار والمعلومات المراد توصيلها للطلاب .

وتتفق هذة النتيجة مـع مـا أشـارة الية كـلا من أحمـا مـاهر ،علي عبد المجيد ،إيمـان مـاهر

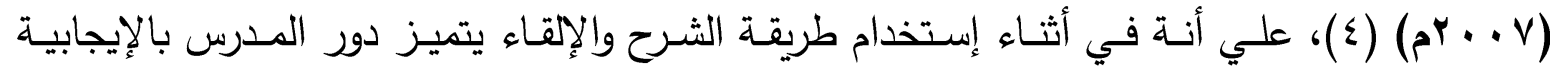
والتلميذ دائما ما يكون متلقي للمعلومات وتتبع هذة الطريقة عدة أشكال يمكن أن يتبعها المدرس تتمثل

ا ـ التحاضـر : ويعرض المدرس الحقائق دون إشـتراك الطـلاب ولاتقدم أي أسئلة إلابعد إنتهاء المحاضرة.

r. الثرح : ومهمتة إظهار أساسيات الموضوع والتدرج من معلومة إلي أخري. r. الوصف : وهي وسيلة للإيضاح اللفظي في حالة عدم توفير الوسلئل الحسيـة. ع. القصص : وهي من الأشياء التي يميل إليها الصغار والكبار وهي تساعد علي جذب إنتباة التلاميذ إلي الدرس .

Miler Fsn And " "ويتفق ذلك أيضا مع نتائج دراسة كلا من ملير فسن "و"سيلون بربكتز Siyn Practies

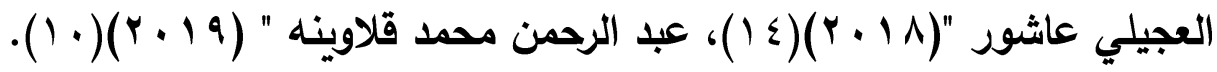
ومن خلال عرض ومناقشة وتفسير نتائج الفرض الثاني يتضـح أنه قد تحقق إجرائيا من خلال تحليل النتائج المطروحة. ثالثا: مناقثة نتائج الفرض الثالث:

توجد فروق ذات دلالـه احصائية بين متوسطي القياسين البعديين للمجموعتين التجربيية والضابطة فى متغيرات ( التنفيذ).لصالح القياس البعدي للمجموعة التجرببية. ويتضح من جدول (T) وجود فروق ذات دلالة إحصائية بين متوسطات القياسات البعدية لدى مجموعتى البحث التجرببيـة و الضـابطة فيعبارات محسور التنفيذ وذلك عند مستوى معنويـة ه . . 
لصالح المجموعة التجريبية حيث تراوحت قيمة ت المحسوبة ما بين ( • (1. الحى .O.VY) وهى قيم

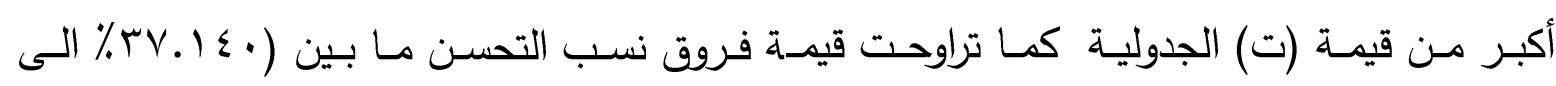
$\cdot(\%$....$r$

ويتضح من جدول (V) وجود فروق ذات دلالة إحصائية بين متوسطات القياسات البعددية للى مجموعتى البحث التجريبية و الضـابطة في محاور واجمالى مقياس مستوى أداء مهارات التنفيذ وذلك عند مستوى معنويـة ه ه . . لصـالح المجموعـة التجريبية حيث تراوحت قيمـة ت المحسوبة مـا بين

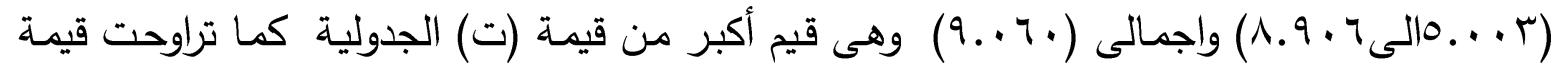

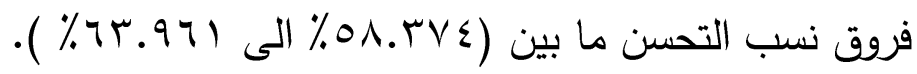
ويوضح جدول (^) أن قيم حجم التأثير لمقياس مهارة التنفيذ بين مجموعتى البحث التجرببية والضـابطة اكبر من (•^. •) وقد حققت قيمة قدرها (qrr.ع) وهى دلالات مرتفعة •مما يدل على فاعليـة البرنـامج المقترح بثـكل مرتفع على تلك المتغيـرات لصـالح المجموعـة التجربيـة عنـة لدى لـى المجموعة الضابطة. ويرجع الباحثون ذلك التحسن في متغيرات المهارات التدريسية (التنفي)قيد البحث لصسالح أفراد المجموعة التجرببية مقارنة بالمجموعة الضـابطة إلي فاعلية البرنامج المقترح بإستخدام التغذية الراجعة والذي يثمل علي تقديم معلومات للطلاب سواء قبل الاداء من خلال تحديد الاغراض المراد تحقيقها بصورة واضحه باعطاء صورة كامله للاداء واعطاء معيار للتقويم والابتعاد عن الشرح اللفظي وتقديم التوجييهات المختصرة كما يتم تقديم ايضـا معلومات اثناء الاداء حيث يركز القائم علي التوجية علي معومات بسيطة غير مطولة كما انها تقدم ايضـا من خلالها معلومات اخري بعد التدريب وتعطي المعلومات للفرد بعد الاداء مباشرة ،الامر الذي الأمرالذي أدي بدورة إلي صقل الطلاب في الجموعة التجريبية بالمعلومات وتبسيطها لهم من خلال تكرارها في اكثر من وقت (قبل - اثناء -بعد) الاداء وإستغلال أنشطة الطلاب وميولهم ورغباتهم وقدراتهم وتوفير بيئة تعليمية تتاسب معظم أفراد المجموعة التجريبية مدا كان لـة الأثر في إستتارة دوافع الطـلاب وزيـادة مشـاركتهم الفعالـة في العملية التعليمية وحثهم علي الاداء الجيد حيث انة من خلال التغذية الراجعة توجية وتقديم تدعيم للطلاب من خلال الاستجابات الحركيـة الناجحة وحذف الحركات الخاطئة ،وهذا يختلف بدورة عن الأسـلوب التقليدي 
(الملاحظة) حيث لا يراعي طبيعة الطلاب المعلمين ولايحفزهم علي الاداء نظرا لان عملية الملاحظه

غير مقننة وغير واضحة ولاتوفر للمتعلمين تكرارالاداء ومعرفة الاخطاء ومحاولة تلاشيها . كما ان تكرار الاداء من خـلال التغذية الراجعة اكثر من مرة سواء قبل اواثتاء او بعد التدريب

يعمل علي صقل المعلومات في ذهن الطالب وبالتالي يحفز ويزيد من ثقتة بنفسة في الاداء . وفي هذا الصدد يشير احمد امين فوزي (ع 9 و ) الي ان للتغذية الراجعة وظائف توجيهية

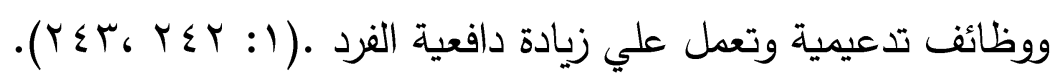

Miler Fsn " ويتفق ذلك أيضا مع نتائج دراسة كلا من " "ملير فسن "و"سيلون بربكتز And Siyn Practies و Heasun Chun""," Hyunjoo Lee,"'Daejoong ويجـونج كـيم

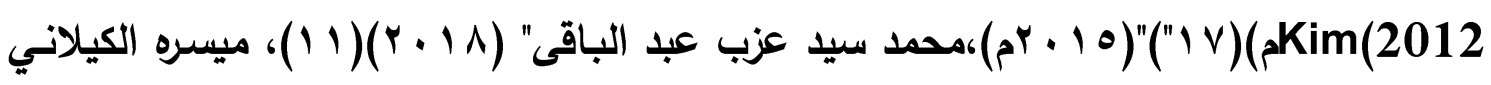

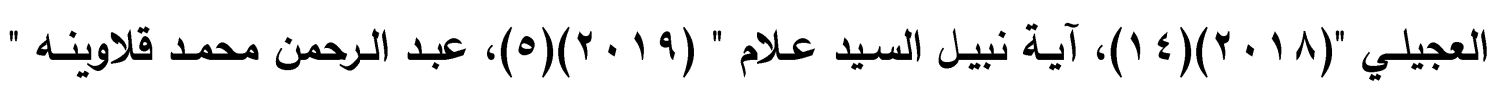
$\cdot(1 \cdot)(r \cdot 19)$

ومن خلال عرض ومناقشة وتفسير نتائج الفرض الثالث يتضح أن الفرض قد تحقق إجرائيا .

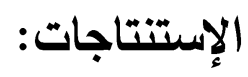
فى حدود عينة البحث وخصائصسها والمجال الذى تم تتفيذفيـة هذا البحث تثير النتائج إلى مايلى: - التغذية الراجعة بوجة عام لها تأثير إيجابى فى تحسين مستوى أداء طالبات الفرقة الرابعة فى تنفيذ وإدارة درس التربية الرياضية . - تقوق المجموعة التجريبية (المستفيدة من التغذية الراجعة المدعمة بإستخدام الفيديو + تحليل الأداء وتصحيح الأخطاء من خلال الموجه) مقارنة بالمجموعة الضابطة فى تنفيذ وإدارة درس التربية الرياضية.

فاعلية إستمارة تقويم طالبة التدريب الميدانى فى المهارات التدريسية (تصميم الباحثون). - - أثارت عملية تقييم مستوى أداء طالبات التدريب الميدانى فى تتفيذ دروس التربية الرياضية بإستخدام لجنة المحكمين بناءا على مشاهدة شرائط الفيديو إلى موضوعية الأسلوب المستخدم فى وضع الدرجة عند تنفيذ جميع أجزاء الدرس. 
فى ضوء نتائج البحث توصى الدراسة بمايلى :

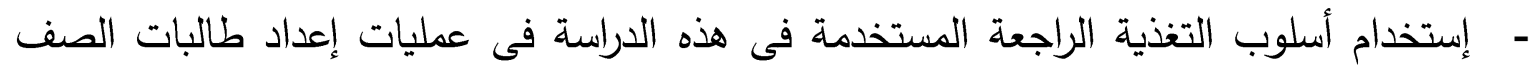
الثانى بكليات التربية الرياضية بحيث تستخدم كأسلوب في تدريس مناهج طرق التدريس العملية. تعميم إستفادة أقسام طرق التدريس والتدريب الميدانى بكليات التربية الرياضية من إستخدام وسائل

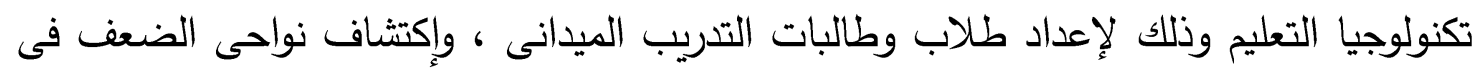
أدائهم وتعديلها . أن أن

- أن يعمل القائمون بالإشراف على طلاب وطالبات التدريب الميدانى بالصف الثالث والرابع على تكليف طلابهم بتنفيذ أنواع الإحماء التى تجنب الطالبات كثرة التعرض لها وتكليفهم أيضا بتدريس مهارات الرياضات الخاصة بالجمباز ومسابقات التدريب الميدان والمضمار . - لفت نظر القائمين على الأشراف بأهمية عمليات التخطيط والتتفيذ والتقويم وإدارة الفصل لما لهما من تأثير إيجابى على تحسين مستوى تتفيذ حصة التربية الرياضية. - إستخدام الفيديو كوسيلة لمعرفة الآداء لتحسين مستوى طلاب وطالبات التدريب الميدانى بالمدارس فى مواقف تدريسية حقيقية. - إجراء دراسات وبحوث تتناول التعرف على تأثير أنواع التغذية الراجعة للتعرف على أنسب توقيت لتقديم التغذية الراجعة وتأثير ذلك على مستوى الآداء فى تتفيذ درس التربية الرياضية.

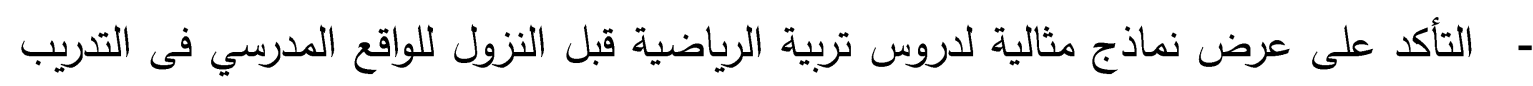
الميدانى لطالبات الصف الثالث والرابع بكليات التربية الرياضية. - - تعيم إستخدام إستمارة تقويم طالبة التدريب الميدانى فى تتفيذ درس التربية الرياضية فى تقييم طلاب وطالبات كليات التربية الرياضية - الفرقة الثالثة والرابعة - أثناء تتفيذهم لاروس التربية الرياضية. - إستخدام أسلوب التدريس المصغر فى التدريب على تتفيذ أجزاء الدروس لطالبات وطلاب الفرقة الثانية بكليات التربية الرياضية. 


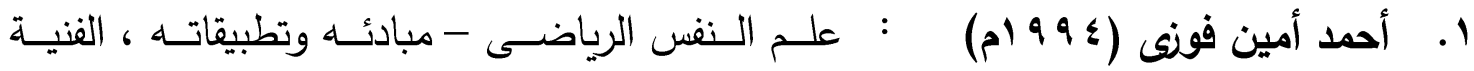
للطباعة والنشر ، الإسكندرية .

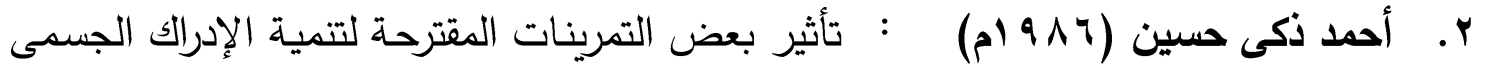
الحركى على مستوى الأداء فى الجمباز ، رسالة دكتوراه

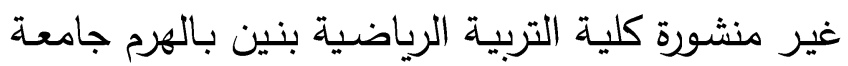

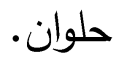

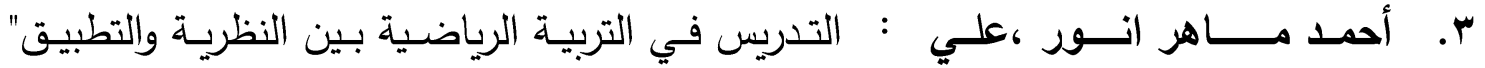

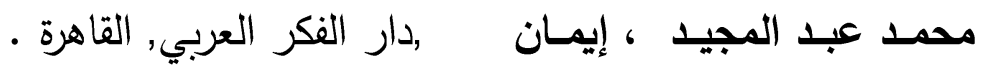

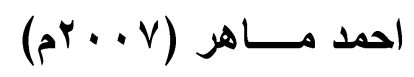

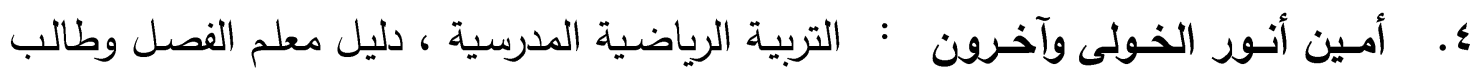

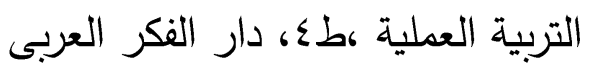
(م) 991 )

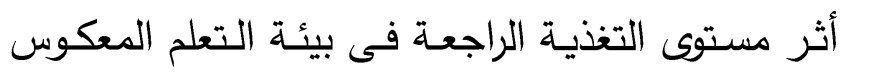

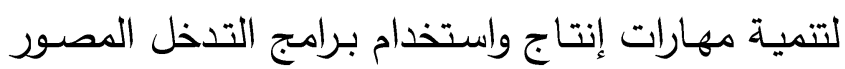
ه. آيــه نبيـل الســيد عـلام $(r+19)$ لدى الطلاب المعلمين شعبة تربية خاصة ، كلية التربية قسم تكنولوجيا التعليم ، جامعة حلوان.

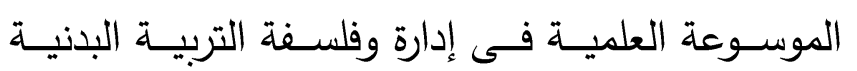

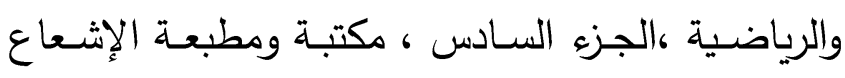
7. حســـن أحمــــد الثــــافعى الفنية ، الاسكندرية . $\left(a^{r} \cdot 1\right)$ طرق التدريس فى التربية الرياضية ، طع، القاهرة دار

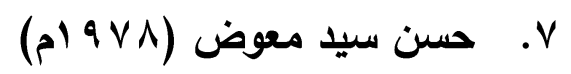

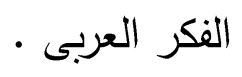

: ادراك المعلم لخصائص محتوى الهندسة للصف الثامن 1. ـ صلاح الخراشى (911)

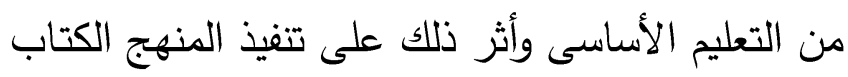
السنوى فى التربية وعلم النفس المجلد (10) دار الثقافة الطباعة ، القاهرة.

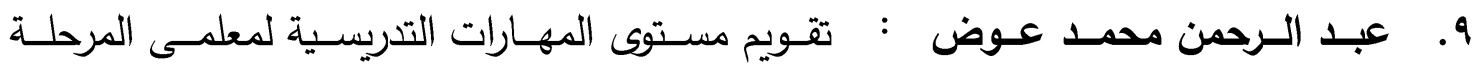


الإبتدائية الأزهريـة فى تدريس مـادة العلوم كليـة التربيـة

$\left(a^{r} \cdots\right)$

$$
\text { جامعة الأزهر - (الإنه }
$$

منهج إلكترونى مقترح لتطوير الكفاءة التدريسية لمعلىى التربية الرياضية بالمرحلة الابتدائية بمحافظة بور سعيد

• 1 . عبـد الـرحمن محمــ قلاونيـة ، كلية التربية الرياضية ،قسم مناهج وطرق التدريس ،

$$
\text { جامعة بور سعيد. }
$$

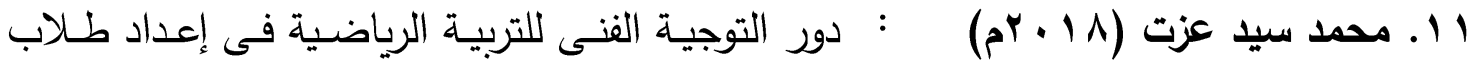
التدريب الميدانى، كليـة التربية الرياضية ،قسم منـاهج

$$
\text { وطرق التدريس ، جامعة بنى سويف. }
$$

r ا . مصطفى عبد السـيع محمد : تكنولوجيا التعليم ، دراسات عربية ، مركز الكتاب للنشر

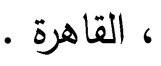

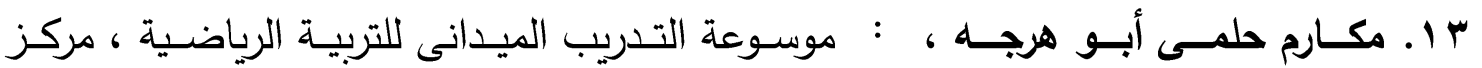

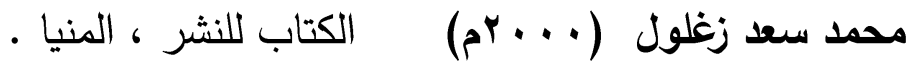

: تـأثير التغذيـة الراجعـة باسـتخدام الوسـائط التكنولوجيـة

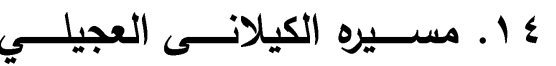
على بعض جوانب التعلم لكرة السـلة لتلاميذ المرحلـة

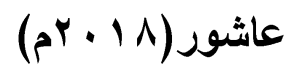
الابتدائيـة بليبيا، كليـة التربيـة الرياضـية للبنـات - قسم مناهج وطرق تدريس ،جامعة الإسكندرية.

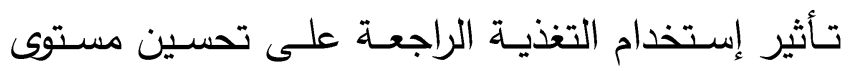
الأداء الحركى للتــويح الجـانبى الــائرى علـى عـش $($ ( ) $99 \wedge)$ الغراب ، رسـالة ماجستير غير منشـورة ، كليـة التربيـة الرياضية للبنين بالقاهرة ، جامعة حلوان

16. Bloom B., et al., : Evaluation to improve Learning, (1981) Mccraw Hill Ny .

17. Heasun Chun, : The Integrated Model Of Smartphone Daejoong Kim , Adoption: Hedonic And Utilitarian Hyunjoo $L$ Lee Value Perceptions Of Smartphones (2012) Among Korean College Student, Department Of Mass Communication 
Konkuk University.

18. Manuel, Austin K. : The Effects of Immediate Feedback $(r \cdot 10)$

Using a Student Response System on Math Achievement of Eleventh Grade Student s, (Doctoral dissertation). Retrieved from Proquest Dissertations and Theses database.

19. Miler Fsn And : Teacher performance competencies for Siyn Practias, vocational preparation, master's degree. (2000)

20. Smith, David., : The Effect of different Schedules of (1991) Feedback (KR) on the Manegment Time of Physical Eduction Student Teachers During Teaching Practice, University of Northern Colorado.

21. Wuest,D.A \& : Foundations of physical education and Bucher,C.A., sport, 13 edition, WCB, McGraw-hill, (1999) Boston.

22. Watson, A. W S : Physical Fitness and Athletic (1995) Performance, Second edition, Longman, London and New York

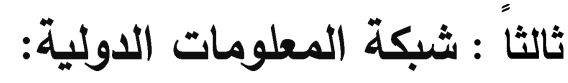

23.http://drgawdat.edutech-portal.net/archives/13600.2016

24.emag.mans.edu.eg 